\title{
Spiritual and religious interventions for well-being of adults in the terminal phase of disease (Review)
}

\author{
Candy B, Jones L, Varagunam M, Speck P, Tookman A, King M
}

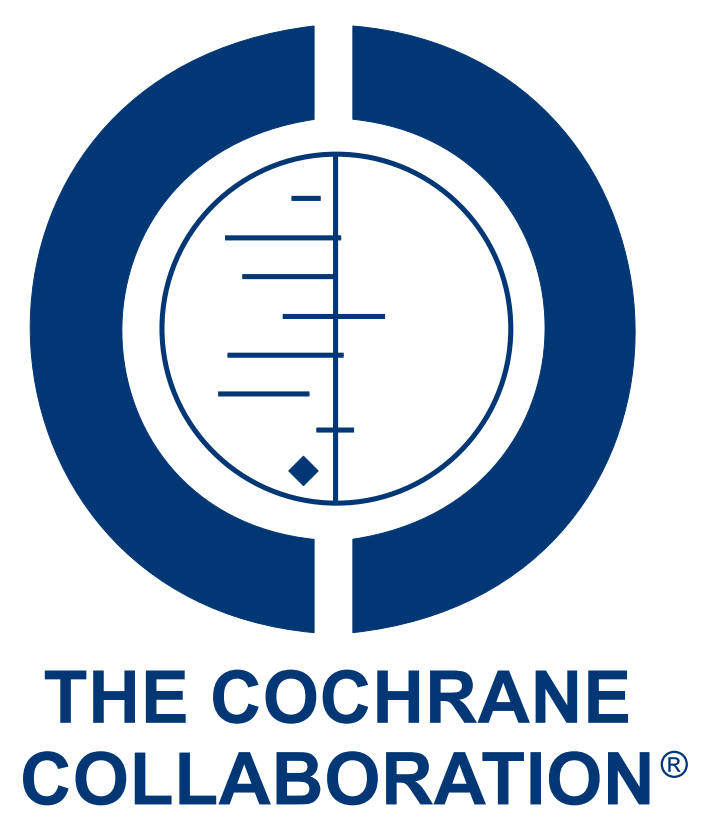

This is a reprint of a Cochrane review, prepared and maintained by The Cochrane Collaboration and published in The Cochrane Library 2012, Issue 5 
TABLE OF CONTENTS

HEADER . . . . . . . . . . . . . . . . . . . . . . . . . . . . . . . . . . . . . . . 1

ABSTRACT . . . . . . . . . . . . . . . . . . . . . . . . . . . . . . . . . . . . . . . . . . . . 1

PLAIN LANGUAGE SUMMARY . . . . . . . . . . . . . . . . . . . . . . . . . . . . . . . . 2

BACKGROUND . . . . . . . . . . . . . . . . . . . . . . . . . . . . . . . . . . . 2

OBJECTIVES . . . . . . . . . . . . . . . . . . . . . . . . . . . . . . . . . . . . . 3

METHODS . . . . . . . . . . . . . . . . . . . . . . . . . . . . . . . . . . . 3

RESULTS . . . . . . . . . . . . . . . . . . . . . . . . . . . . . . . . . . . . . . . 7

Figure 1. . . . . . . . . . . . . . . . . . . . . . . . . . . . . . . . . . . . . . 8

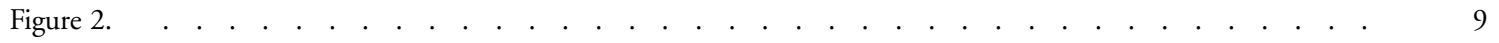

DISCUSSION . . . . . . . . . . . . . . . . . . . . . . . . . . . . . . . . . . . . . 12

AUTHORS' CONCLUSIONS . . . . . . . . . . . . . . . . . . . . . . . . . . . . . . . . . . . . . . 13

ACKNOWLEDGEMENTS . . . . . . . . . . . . . . . . . . . . . . . . . . . . . . . . . . . . . . . 14

REFERENCES . . . . . . . . . . . . . . . . . . . . . . . . . . . . . . . . . . . . . 15

CHARACTERISTICS OF STUDIES . . . . . . . . . . . . . . . . . . . . . . . . . . . . . . . . . . . 17

DATA AND ANALYSES . . . . . . . . . . . . . . . . . . . . . . . . . . . . . . . . . . . . . . . . . . . . . . 26

Analysis 1.1. Comparison 1 Comparison one: Meditation, Outcome 1 Quality of life at 9 weeks; meditation versus massage. . . . . . . . . . . . . . . . . . . . . . . . . . . . . . . . . . . . . 28

Analysis 1.2. Comparison 1 Comparison one: Meditation, Outcome 2 Quality of life at 9 weeks; meditation versus friendly visits. . . . . . . . . . . . . . . . . . . . . . . . . . . . . . . . . . . . 28

Analysis 1.3. Comparison 1 Comparison one: Meditation, Outcome 3 Quality of life at 8 weeks (mean change); meditation. . . . . . . . . . . . . . . . . . . . . . . . . . . . . . . . . . .

Analysis 1.4. Comparison 1 Comparison one: Meditation, Outcome 4 Quality of life at 68 weeks (mean change); meditation.

Analysis 1.5. Comparison 1 Comparison one: Meditation, Outcome 5 Interpersonal relationships at 8 weeks (mean change); meditation.

Analysis 1.6. Comparison 1 Comparison one: Meditation, Outcome 6 Interpersonal relationships at 68 weeks (mean change); meditation.

Analysis 1.7. Comparison 1 Comparison one: Meditation, Outcome 7 Physical function at 8 weeks (mean change); meditation. . . . . . . . . . . . . . . . . . . . . . . . . . . . . . . . . . .

Analysis 1.8. Comparison 1 Comparison one: Meditation, Outcome 8 Physical function at 68 weeks (mean change); meditation.

Analysis 1.9. Comparison 1 Comparison one: Meditation, Outcome 9 Quality of life at 8 weeks (mean change); meditation and massage. . . . . . . . . . . . . . . . . . . . . . . . . . . . . . . . . . . .

Analysis 1.10. Comparison 1 Comparison one: Meditation, Outcome 10 Quality of life at 68 weeks (mean change); meditation and massage. . . . . . . . . . . . . . . . . . . . . . . . . . . . . . . . . .

Analysis 1.11. Comparison 1 Comparison one: Meditation, Outcome 11 Physical function at 8 weeks (mean change); meditation and massage.

Analysis 1.12. Comparison 1 Comparison one: Meditation, Outcome 12 Physical function at 68 weeks (mean change); meditation and massage.

Analysis 1.13. Comparison 1 Comparison one: Meditation, Outcome 13 Interpersonal relationships at 8 weeks (mean change); meditation and massage. . . . . . . . . . . . . . . . . . . . . . . . . . . .

Analysis 1.14. Comparison 1 Comparison one: Meditation, Outcome 14 Interpersonal relationships at 68 weeks (mean change); meditation and massage. . . . . . . . . . . . . . . . . . . . . . . . . . . . . . . . . . . 34

Analysis 1.15. Comparison 1 Comparison one: Meditation, Outcome 15 Well-being at 8 weeks (mean change); meditation.

Analysis 1.16. Comparison 1 Comparison one: Meditation, Outcome 16 Well-being at 68 weeks (mean change); meditation.

Analysis 1.17. Comparison 1 Comparison one: Meditation, Outcome 17 Well-being at 8 weeks (mean change); meditation and massage. . . . . . . . . . . . . . . . . . . . . . . . . . . . . . . . . . . . 36

Analysis 1.18. Comparison 1 Comparison one: Meditation, Outcome 18 Well-being at 68 weeks (mean change); meditation and massage. 
Analysis 1.19. Comparison 1 Comparison one: Meditation, Outcome 19 Physical symptoms at 8 weeks (mean change); meditation.

Analysis 1.20. Comparison 1 Comparison one: Meditation, Outcome 20 Physical symptoms at 68 weeks (mean change); meditation.

Analysis 1.21. Comparison 1 Comparison one: Meditation, Outcome 21 Physical symptoms 8 weeks (mean change); meditation and massage. . . . . . . . . . . . . . . . . . . . . . . . . . . . . . .

Analysis 1.22. Comparison 1 Comparison one: Meditation, Outcome 22 Physical symptoms at 68 weeks (mean change); meditation and massage.

Analysis 1.23. Comparison 1 Comparison one: Meditation, Outcome 23 Transcendence at 8 weeks (mean change); meditation.

Analysis 1.24. Comparison 1 Comparison one: Meditation, Outcome 24 Transcendence at 68 weeks (mean change); meditation.

Analysis 1.25. Comparison 1 Comparison one: Meditation, Outcome 25 Transcendence at 8 weeks (mean change); meditation and massage. . . . . . . . . . . . . . . . . . . . . . . . . . . . . . .

Analysis 1.26. Comparison 1 Comparison one: Meditation, Outcome 26 Transcendence at 68 weeks (mean change); meditation and massage.

Analysis 2.1. Comparison 2 Comparison two: Multi-disciplinary interventions involving the support of a chaplain, Outcome 1 Emotional support.

Analysis 2.2. Comparison 2 Comparison two: Multi-disciplinary interventions involving the support of a chaplain, Outcome 2 Quality of life.

Analysis 2.3. Comparison 2 Comparison two: Multi-disciplinary interventions involving the support of a chaplain, Outcome 3 Symptom severity.

Analysis 2.4. Comparison 2 Comparison two: Multi-disciplinary interventions involving the support of a chaplain, Outcome 4 Spiritually support. . . . . . . . . . . . . . . . . . . . . . . . . . . . .

Analysis 2.5. Comparison 2 Comparison two: Multi-disciplinary interventions involving the support of a chaplain, Outcome 5 Clinic visits.

Analysis 2.6. Comparison 2 Comparison two: Multi-disciplinary interventions involving the support of a chaplain, Outcome 6 Urgent care visits.

Analysis 2.7. Comparison 2 Comparison two: Multi-disciplinary interventions involving the support of a chaplain, Outcome 7 Hospital admissions. . . . . . . . . . . . . . . . . . . . . . . . . . . .

Analysis 2.8. Comparison 2 Comparison two: Multi-disciplinary interventions involving the support of a chaplain, Outcome 8 Emergency department visits. . . . . . . . . . . . . . . . . . . . . . . . . .

Analysis 2.9. Comparison 2 Comparison two: Multi-disciplinary interventions involving the support of a chaplain, Outcome 9 Specialist visits.

Analysis 2.10. Comparison 2 Comparison two: Multi-disciplinary interventions involving the support of a chaplain, Outcome 10 Total hospital days.

Analysis 2.11. Comparison 2 Comparison two: Multi-disciplinary interventions involving the support of a chaplain, Outcome 11 Admissions to intensive care.

Analysis 2.12. Comparison 2 Comparison two: Multi-disciplinary interventions involving the support of a chaplain, Outcome 12 Satisfaction of care environment.

Analysis 2.13. Comparison 2 Comparison two: Multi-disciplinary interventions involving the support of a chaplain, Outcome 13 Satisfaction with care staff. . . . . . . . . . . . . . . . . . . . . . . . . .

APPENDICES . . . . . . . . . . . . . . . . . . . . . . . . . . .

HISTORY . . . . . . . . . . . . . . . . . . . . . . . . . . . . . . . . .

CONTRIBUTIONS OF AUTHORS . . . . . . . . . . . . . . . . . . . . . . . . . . . . . . . . .

DECLARATIONS OF INTEREST . . . . . . . . . . . . . . . . . . . . . . . . . . . . . .

SOURCES OF SUPPORT . . . . . . . . . . . . . . . . . . . . . . . . . . . . . . . . .

DIFFERENCES BETWEEN PROTOCOL AND REVIEW

INDEX TERMS 


\title{
Spiritual and religious interventions for well-being of adults in the terminal phase of disease
}

\author{
Bridget Candy ${ }^{1}$, Louise Jones ${ }^{1}$, Mira Varagunam ${ }^{1}$, Peter Speck $^{2}$, Adrian Tookman ${ }^{1}$, Michael King ${ }^{3}$ \\ ${ }^{1}$ Marie Curie Palliative Care Research Unit, UCL Mental Health Sciences Unit, University College Medical School, London, UK. \\ ${ }^{2}$ Cicely Saunders Institute, King's College London, London, UK. ${ }^{3}$ UCL Mental Health Sciences, University College Medical School, \\ London, UK
}

Contact address: Bridget Candy, Marie Curie Palliative Care Research Unit, UCL Mental Health Sciences Unit, University College Medical School, Charles Bell House, 67 - 73 Riding House Street, London, W1W 7EJ, UK. b.candy@ucl.ac.uk. bridget@metaclarity.com.

Editorial group: Cochrane Pain, Palliative and Supportive Care Group.

Publication status and date: New, published in Issue 5, 2012.

Review content assessed as up-to-date: 4 April 2012.

Citation: Candy B, Jones L, Varagunam M, Speck P, Tookman A, King M. Spiritual and religious interventions for well-being of adults in the terminal phase of disease. Cochrane Database of Systematic Reviews 2012, Issue 5. Art. No.: CD007544. DOI: 10.1002/14651858.CD007544.pub2.

Copyright (c) 2012 The Cochrane Collaboration. Published by John Wiley \& Sons, Ltd.

\section{A B S T R A C T}

\section{Background}

As terminal disease progresses, health deteriorates and the end of life approaches, people may ask "Why this illness? Why me? Why now? "Such questions may invoke, rekindle or intensify spiritual or religious concerns. Although the processes by which these associations occur are poorly understood, there is some research evidence for associations that are mainly positive between spiritual and religious awareness and wellness, such as emotional health.

\section{Objectives}

This review aimed to describe spiritual and religious interventions for adults in the terminal phase of a disease and to evaluate their effectiveness on well-being.

\section{Search methods}

We searched 14 databases to November 2011, including the Cochrane Central Register of Controlled Trials and MEDLINE.

\section{Selection criteria}

We included randomised controlled trials (RCTS) if they involved adults in the terminal phase of a disease and if they evaluated outcomes for an intervention that had a spiritual or religious component. Primary outcomes were well-being, coping with the disease and quality of life.

\section{Data collection and analysis}

In accordance with the inclusion criteria, two review authors independently screened citations. One review author extracted data which was then checked by another review author. We considered meta-analysis for studies with comparable characteristics. 


\section{Main results}

Five RCTs (1130 participants) were included. Two studies evaluated meditation, the others evaluated multi-disciplinary palliative care interventions that involved a chaplain or spiritual counsellor as a member of the intervention team. The studies evaluating meditation found no overall significant difference between those receiving meditation or usual care on quality of life or well-being. However, when meditation was combined with massage in the medium term it buffered against a reduction in quality of life. In the palliative care intervention studies there was no significant difference in quality of life or well-being between the trial arms. Coping with the disease was not evaluated in the studies. The quality of the studies was limited by under-reporting of design features.

\section{Authors' conclusions}

We found inconclusive evidence that interventions with spiritual or religious components for adults in the terminal phase of a disease may or may not enhance well-being. Such interventions are under-evaluated. All five studies identified were undertaken in the same country, and in the multi-disciplinary palliative care interventions it is unclear if all participants received support from a chaplain or a spiritual counsellor. Moreover, it is unclear in all the studies whether the participants in the comparative groups received spiritual or religious support, or both, as part of routine care or from elsewhere. The paucity of quality research indicates a need for more rigorous studies.

\section{PLAIN LANGUAGE SUMMARY}

\section{Spiritual and religious interventions for adults in the latter stage of a disease}

Being ill and near to the end of life can raise questions such as "Why me? Why now?". The experience may start or increase thoughts of a spiritual or religious nature. Some research has found that having spiritual or religious awareness, or both, may help a person cope with disease and dying. We conducted our review through searches for studies that were randomised controlled trials. We only included such studies if they evaluated an intervention that involved a spiritual or religious aspect, such as prayer and meditation, and aimed to support adults in the terminal phase of a disease. We found five studies. In total, the studies involved 1130 participants. Two studies evaluated meditation. Three evaluated the work of a palliative care team that involved physicians, nurses and chaplains. Studies compared those who received the intervention with those who did not. Studies evaluated the interventions in various ways including whether it helped in any way a person's quality of life.

There was inconclusive evidence that meditation and palliative care teams that involve a chaplain or spiritual counsellor help patients feel emotionally supported. The findings of the review are limited. This is because none of the studies measured whether the intervention helped the person cope with the disease process, and also it is unclear whether all participants receiving the palliative care team interventions were offered support from a chaplain. All the studies were undertaken in one country, making it difficult to draw conclusions as to whether the intervention would work elsewhere.

\section{B A C K G R O U N D}

Religion is an organised system of beliefs, practices, rituals and symbols that can be seen to be designed to (a) facilitate closeness to the sacred or transcendent being (God, higher power or ultimate truth/reality) and (b) foster an understanding of one's relationship and responsibility to others in living together in a community (Koenig 2001; Larson 1998). Participating in religious activities may include personal benefits in terms of promotion of social, cultural, economic and political concerns. Religion and spirituality were regarded as identical until recent times (Hill 2000). The ad- vent of the 20th century saw a gradual distinction between religion as practices and beliefs about the sacred or divine, and spirituality, which in contrast is defined with less clarity. The broader use of the term 'spiritual' can relate to non-religious concerns involving existential and emotional experience. While spirituality and religion may be differentiated they are, nevertheless, still inter-related. Spirituality and religiosity can be seen to link the personal to the universal and both can include striving for coherence, meaning and purpose in human life. Religion is the practice of spiritual belief, but spiritual concerns, such as searching for meaning in life, 
may occur in the absence of any religious affiliation or practice (King 2006; Speck 1998).

\section{Description of the condition}

The experience of ill health, particularly near the end of life may, by raising questions such as "Why? Why me? Why now?" invoke, rekindle or intensify spiritual or religious concerns, or both. Although the processes by which these associations occur are poorly understood there is some research evidence, mainly from US and UK populations, for mainly positive associations between spiritual and religious awareness and wellness, such as emotional and mental health (see for instance Balboni 2007; Cardella 2004; Kendler 2003; King 1999; Koenig 2001; Miller 2003; Walsh 2002). At such time spiritual or religious belief may help a person cope by facilitating renewed hope and peace of mind by providing a way to grieve impending death, find meaning and purpose and adjust to otherwise insoluble problems, such as the effect their death will have on their friends and family. It may also protect against psychological morbidity and enhance quality of life (McClain 2003; Tarakeshwar 2006). Research evidence for this is reflected in the NICE guidance on 'Improving supportive and palliative care for adults with cancer' (NICE 2004) and the development of the Liverpool Care Pathway, which provides a framework for transfer of care from a hospice to a general health setting (LCP) (Ellershaw 2003). Both these endeavours are based on the best available evidence and both recommend offering spiritual support services.

\section{Description of the intervention}

Despite policy, practical guidelines (as reflected in NICE 2004) and research now routinely suggesting spiritual and religious needs are essential components, as opposed to additional services provided by others such as Chaplaincy, of end-stage health care. Also many physicians believe spiritual or religious awareness has a generally positive effect on the well-being of patients in the terminal phase of a disease (see for instance Curlin 2007; Larimore 2002; Sloan 2000). In addition a significant proportion of such patients greatly value the opportunity to discuss spiritual or religious issues with health professionals (MacLean 2003; McClain 2003; McCord 2004; Murray 2004). However, beyond referral to a Chaplain or other religious representatives, discussions on spiritual or religious needs between the patient and the health professional do not always take place (Curlin 2007).

The recognition that health professionals should help facilitate spiritual or religious support is relatively recent and health professionals are unclear how to go about this (Lo 2002). For instance, does expressing frustration, fear, feeling useless or feeling life is not worthwhile suggest a need for spiritual or religious support? Does the patient need to be offered religious services to pray, to talk with someone about spiritual issues, or perhaps be around people who share the same belief system (Hampton 2007)? Health professionals may also feel unskilled to judge. A lack of adequate training in major religious denominations and spiritual needs and time constraints are barriers for discussions by professionals and health professionals may be unclear where the professional boundaries lie between the health professional and the chaplain (Walter 1997). Professionals may also fear that such a discussion will distress, harm or offend the patient, such as for those with no religious faith. Discussion of spiritual or religious issues may also conflict with health professionals' own views; some professionals may be atheist or may be reluctant to discuss spirituality and religious issues with patients, or both. However, this needs careful consideration, just as we may not approve of highly spiritual staff imposing their views on patients, we are also sensitive to the dangers of the converse. However, all staff should be capable of at least listening to patients' concerns of whatever nature.

\section{Why it is important to do this review}

Facilitating spiritual awareness and any other religious needs may be a worthwhile intervention within health services. There is some emerging randomised controlled trial (RCT) evidence on a number of interventions involving spiritual or religious components for patients with advanced disease. These include meditation and interventions that aim to support or facilitate spiritual or religious awareness by supportive group discussion. However, research in this area inevitably suffers from a tension in that controlled evaluations of this kind may be inappropriate in a patient group that has high emotional, mental and physical needs, and for whom spiritual and/or religious needs may also be being provided for from outside the healthcare setting.

\section{O B JECT I VES}

This systematic review aimed:

1. to classify and describe spiritual and religious interventions for adults in the terminal phase of a disease;

2. to evaluate effectiveness of spiritual and religious interventions for adults in the terminal phase of a disease.

\section{MET HODS}

\section{Criteria for considering studies for this review}

\section{Types of studies}


We included randomised controlled trials (RCTs). As we anticipated few RCTs we also aimed to include quasi-RCTs, controlled before and after studies and interrupted time series studies.

Studies undertaken in the community or any healthcare setting were included. We included studies in any languages. Due regard was taken in our discussion of all relevant studies to the cultural traditions and influences that may affect the articulation of religious and spiritual thought and need.

\section{Types of participants}

Participants were aged 16 and over, of either sex and:

1. were in the terminal phase of a chronic and progressive lifethreatening disease including but not limited to cancers. We defined terminal as an estimated life expectancy of less than a year; or

2. had a life-threatening disease with poor prognosis, such as advanced heart failure or dementia, and were receiving palliative care.

Participants may or may not have held, or practised, any type of religious or spiritual belief.

\section{Types of interventions}

We included studies if they evaluated patient outcomes for spiritual or religious interventions. By spiritual or religious interventions we mean those that contain at least some reference to beliefs and/or experiences in a realm that transcends the material world and/or daily experiences (King 2009). Furthermore, we mean beliefs and/or experiences that go beyond the universal 'search for meaning' that is a part of all psychotherapy and often pertains to values such as family life, relationships and work. Eligible interventions may include those which work with the set of spiritual or religious beliefs/understandings that patients bring with them. However, interventions were not determined by patients' beliefs and could include any particular spiritual or religious form, such as prayer, pastoral care from a religious leader, interventions involving discussions of spiritual or religious concerns, expanded consciousness or those described as transcending everyday experiences. We also included yoga but not purely physical forms, which are more often used as forms of exercise to increase exercise and suppleness. We included meditation on the basis that it usually induces a mode of consciousness that goes beyond the everyday and involves self realisation and/or meaning (Feuerstein 2006). We also included pastoral care from a Chaplain or other religious/ spiritual representative. Although we are aware that such services go beyond spiritual/religious concerns by including, befriending and supporting people in their everyday concerns, very few socalled spiritual interventions do not include other components. For example, prayer contains psychological elements of relaxation and self expression; cognitive behavioural therapy modified to take account of religious beliefs obviously still contains many psychological ingredients.
We included interventions that were multi-component where the spiritual or religious intervention was specified as one of several components.

We did not include interventions on recreational drugs, such as cocaine and amphetamines, whose actions similar to known neurotransmitters may lead to experiences that are attributed to a spiritual cause (Hay 1987). We did not consider interventions where the patient was not actively involved, such as distant intercessory prayer in which the patient is not involved in face-to-face contact or in communication with the intervention provider. We also did not include alternative and complementary medicine interventions that assessed a spiritual outcome but were not described, by the developers of the intervention, as having a spiritual or religious component. Nor did we include studies of interventions that measured outcomes relating to spiritual well-being but did not fulfil our definition of a spiritual or religious intervention.

The principal comparison included usual care and other types of supportive interventions that did not have an explicit spiritual component, such as complementary therapies like massage or forms of psychotherapy. In our data extraction we took care to gather all available details of comparison care. The types of comparison care identified were reflected in our analysis plan and in our subsequent conclusions.

\section{Types of outcome measures}

We assessed primary and secondary outcomes in light of the population samples' characteristics, including culture and demography, as well as the characteristics of the intervention including how the intervention was structured, who delivered it, and whether they were a member of a religious or spiritual group, a health professional or other type of person. We noted where spiritual or religious care might also have been available to those in the comparison group.

\section{Primary outcomes}

Spiritual and religious interventions may impact on patients in a number of important ways and thus we expected the nature of the primary outcomes to vary. However, we are aware such broadness may complicate the conclusions we are able to draw.

The primary outcome measures were the effect of the intervention on well-being (this may include psychological well-being, common mental disorder or death distress), coping (defined for the purposes of this review as enhancing the ability to live with the effects of the disease process) and quality of life. Such outcomes were captured using validated scales such as, in the case of depression, the Hamilton Rating Scale for Depression.

\section{Secondary outcomes}

Secondary outcomes included physical symptoms such as pain, fatigue, hypersomnia and breathlessness; health service use such 
as hospital admission and discharge; mortality and place of death, as well as spiritual well-being and informal carer outcomes. Such outcomes may have been captured using validated scales that measured, for example, spirituality or religion awareness, values or involvement (Hill 1999), or use of health services.

\section{Search methods for identification of studies}

\section{Electronic searches}

We searched the following databases.

- The Cochrane Central Register of Controlled Trials

(CENTRAL) Issue 10, 2011

- MEDLINE 1950 to November 2011

- PSYCINFO 1806 to November 2011

- EMBASE 1980 to November 2011

- AMED 1985 to November 2011

- CINAHL 1981 to November 2011

- National Health Service Research Register, searched from inception (2000) to closure (September 2009)

- ATLA Religion Database 1949 to November 2011

- ASSIA: Applied Social Sciences Index and Abstracts 1987 to November 2011

- Anthropology Plus 1980 to November 2011

- Social Services Abstracts 1979 to November 2011

- Sociological Abstracts 1952 to November 2011

The search strategies are detailed in Appendix 1.

\section{Searching other resources}

We checked the conference abstract books of the European Association of Palliative Care from 2007 to 2011 . We undertook forward and backward citation checks on all included studies.

\section{Data collection and analysis}

\section{Selection of studies}

Two review authors (BC and $\mathrm{LJ}$ ) independently screened citations of studies in accordance with the defined inclusion criteria. Following screening, two review authors (BC and $\mathrm{LJ}$ ) independently assessed the full text of eligible citations for inclusion. Differences of opinion were resolved by consensus with the other review authors (MK, PS and AT). If resolution was not possible, we attempted to contact the authors for clarification. We documented justification for excluding studies at this stage.

\section{Data extraction and management}

One review author extracted the data and another (BC and LJ) then checked this. The other review authors (PS, MK and AT) were consulted regarding any discrepancies and we resolved these by consensus.

We designed a data extraction form for this review. Where possible, we obtained the following information for each study:

1. Type of study design.

2. The number of participants eligible, number randomised/ recruited and reasons why participants were not included in the trial.

3. The number of participants evaluated at follow-up(s) and timing of follow-up time points.

4. Participant characteristics including age, sex, terminal disease, co-morbidities and spiritual or religious practice and beliefs.

5. Trial design in terms of masking, whether parallel or crossover, features of randomisation and sample size calculation.

6. Type of spiritual or religious intervention, including practice and belief system, who delivered it, duration and mode of delivery.

7. Comparison intervention including content, duration and mode and whether any additional spiritual or religious practices, such as hospital chaplaincy, were available and if so their take-up.

8. Outcome data at all time points including how they were measured and the mean or categorical scores of the main and other outcomes.

Where information was lacking, we attempted to make contact with trial authors or trial sponsors.

One review author (BC) entered the extracted data in to RevMan 5 (RevMan 2011) and a second review author checked the data; specifically $\mathrm{LJ}$ checked entries on trial description and MV checked entries on trial findings. The other review authors (MK and PS) were consulted regarding any discrepancies and these were resolved by consensus.

\section{Assessment of risk of bias in included studies}

Two review authors (BC and MV) independently assessed the quality of included RCTs according to the criteria described in the Cochrane Handbook for Systematic Reviews of Interventions ( Higgins 2011) and supported by Juni 2001. Where differences of opinion existed we resolved them by consensus with the other review authors (MK, PS and AT).

We assessed four main sources of systematic bias using the 'Risk of bias' tool for each included study:

- selection bias (bias at recruitment, randomisation sequence, concealment of allocation);

- performance bias;

- detection bias;

- attrition bias (the completeness of follow-up, with less than $10 \%$ loss to follow-up defined as adequate). 
Based on this criteria, we broadly subdivided studies into the following three categories:

- all quality criteria met: low risk of bias;

- one or more of the quality criteria only partly met: moderate risk of bias; and

- one or more criteria not met: high risk of bias.

\section{Measures of treatment effect}

Studies measuring treatment effect used either dichotomous data or an ordinal rating scale such as, for psychological status, the Hospital Anxiety and Depression Scale (HADS) or Beck Depression Inventory (BDI).

\section{Dichotomous data}

Where dichotomous data were reported, we extracted or generated odds ratios (ORs) and their 95\% confidence intervals (CI).

\section{Continuous data}

We assessed effects measures for ordinal data as continuous data. We generated the mean difference (MD) for ordinal data where the data were provided as a mean and standard deviation (SD).

\section{Dealing with missing data}

Missing studies can result from an inadequate search for data or from publication bias in that papers with negative findings are less likely to be published. How we dealt with identifying missing studies is discussed in the section on the search strategy.

A significant amount of loss to follow-up was expected to have occurred in the studies in this review, due to the patient's declining health. We report attrition rates, per study, in the 'Risk of bas' tables. This includes, if available, per trial arm reasons for attrition and whether the study stated any re-inclusions performed in analyses.

A common item missing in outcome data is the standard deviation (SD) for continuous outcome. Where data were not reported, but might be available we attempted to contact the study authors. If contact with the author was not possible, we planned to calculate or impute it using relevant data, only if a minority of the studies (to be combined in a meta-analysis) had a missing SD (Higgins 2011). We also planned to test any such imputation in sensitivity analyses to assess its impact on combined analysis.

We did not exclude studies on the basis of missing data. In the discussion section we address the potential impact of missing data on the findings of the review.

\section{Assessment of heterogeneity}

If meta-analysis had been possible, we would have assessed statistical heterogeneity between studies using the $\mathrm{Chi}^{2}$ test and I 2 statistic (a Chi ${ }^{2} \mathrm{P}$ value of less than 0.05 indicates significant heterogeneity and an $\mathrm{I}^{2}$ statistic greater than $50 \%$ indicates substantial variability in the effect estimate between studies that is due to heterogeneity). If heterogeneity was identified we undertook subgroup analysis to explore the lack of homogeneity.

\section{Assessment of reporting biases}

We planned to explore publication bias by using funnel plots. We realise, however, that publication bias is only one of a number of possible causes of funnel plot asymmetry.

\section{Data synthesis}

We were aware that there was likely to be a wide range of types of interventions and comparisons groups that would limit the number of studies that could be combined in a meta-analysis. Where study data were of sufficient quality (a study met at least one of the four a priori quality criteria) and were sufficiently similar (in intervention, outcome measure and type of analysis) we planned to combine data in a meta-analysis to provide a pooled effect estimate. We would have used a fixed-effect model in the first instance. If there was no statistical heterogeneity, we used a randomeffects model to check the robustness of the fixed-effect model. If statistical heterogeneity was observed, we used the random-effects model a priori.

\section{Subgroup analysis and investigation of heterogeneity}

To explore clinical heterogeneity and investigate the effect modification of participants and treatment types, we planned, if there were sufficient data, to perform the following subgroup analyses:

\section{Participants}

1. Gender - male or female

2. By type of disease, for example cancer, HIV or cardiovascular disease

3. Age

4. By type of spiritual beliefs (including prior and current)

\section{Intervention}

1. Type of spirituality or religious intervention including whether the intervention explicitly works with patients' beliefs or is independent of their beliefs

2. Whether the practitioner delivering the intervention is accredited to provide spiritual and/or religious support

3. Whether spirituality was a component of a multi-faceted intervention 


\section{Duration/intensity}

\section{Sensitivity analysis}

We planned to perform sensitivity analyses by excluding:

1. unpublished studies (if there were any);

2. studies with a higher risk of bias;

3. studies that used scales that were not validated to measure effect.

\section{RE S U L T S}

\section{Description of studies}

See: Characteristics of included studies; Characteristics of excluded studies.

We identified 3868 citations from our electronic search. From the screening of titles and abstracts we identified 13 studies that were potentially relevant. On full-text retrieval five eligible RCTs matched our inclusion criteria (Brumley 2007; Downey 2009; Gade 2008; Rabow 2004; Williams 2005). We identified no quasiRCTs, controlled before and after studies or interrupted time series studies. We excluded five of the eight studies after reading the full text because the participants were not in the terminal phase of a disease. We excluded the other two because their interventions did not fit our criteria; one as it was a form of Chinese herbal medicine and the other as the intervention was whether an actor is as effective as a person with self declared healing powers in the laying on of hands. See the 'Characteristics of excluded studies' table. The other studies fitted our criteria of being a spiritual or religious intervention because two were on meditation (Downey 2009; Williams 2005) and three were end of life programmes of care that involved the work of a chaplain or spiritual counsellor in regards to spiritual support or concerns (Brumley 2007; Gade 2008; Rabow 2004). These five studies involved 1130 participants. All five were undertaken in North American populations; none of the studies provided details on participants' religion and spiritual beliefs. All trialists stated that a reason for undertaking the research was that earlier research suggested that the intervention may be beneficial; none gave other reasons, such as theoretical underpinning of its components.

\section{Participants}

In three studies the participants received, either as usual care or as part of the evaluated intervention, palliative care (Brumley 2007; Downey 2009; Rabow 2004); in one study participants had advanced disease (Williams 2005) and in another they were hospitalised with a life-limiting illness (Gade 2008). Four studies included patients with cancer as well as patients with other diagnoses
(Brumley 2007; Downey 2009; Gade 2008; Rabow 2004). With regard to prognosis, participants had:

- cancer, heart or pulmonary disease with a prognosis of approximately one year or less to live (Brumley 2007);

- AIDS or cancer with a survival prognosis up to six months (Downey 2009);

- cancer, heart or pulmonary disease, end-stage renal disease, organ failure, stroke or dementia and were those whose attending physician indicated that they 'would not be surprised if the patient died within a year' (Gade 2008);

- cancer, heart or pulmonary disease with a life expectancy of one to five years (Rabow 2004);

- HIV-1 that was either late-stage AIDS or they had a comorbidity that was late stage (Williams 2005).

Where reported, the mean age of participants per trial or trial arm ranged from 42 to 74 years.

\section{Setting}

The settings of the studies varied. In two studies the interventions were provided mostly in a patient's home (Brumley 2007; Downey 2009), while of the remainder one was provided in a general medicine outpatient clinic (Rabow 2004), one in a dedicated inpatient nursing facility (Williams 2005) and one in a general hospital (Gade 2008).

\section{Intervention}

The studies varied in intervention content and duration. Two were of meditation provided by a qualified instructor (Downey 2009; Williams 2005). In one study the patient met with the meditation instructor up to twice a week and this continued until the patient's death or voluntary withdrawal (Downey 2009). In the other study the patient met with the instructor once for a 90-minute introductory group class on the principles of Metta meditation (Williams 2005). The participants were instructed to follow the meditation exercise taught in this class at least daily for four weeks.

The other three studies were of multi-disciplinary palliative care team interventions that involved the support of a chaplain or a spiritual counsellor (Brumley 2007; Gade 2008; Rabow 2004). Other members of the team included physicians, nurses and social workers, in one study in addition to a pharmacist, psychologist, art therapist and volunteers (Rabow 2004). None of the multidisciplinary studies reported how much contact time patients had with the chaplain, or if all patients had access to the team chaplain. One study provided the intervention until the patient's death ( Brumley 2007), another for the duration of the hospital stay (Gade 2008) and in the other for 12 months (Williams 2005).

\section{Comparison}


The studies varied in comparison group. Participants randomised to the comparative groups received the following.

- In three studies usual care only (Brumley 2007; Gade 2008; Rabow 2004). In one this involved attending a general medicine outpatient clinic (Rabow 2004), in one various amounts and types of home healthcare services, acute care, primary care and hospice care (Brumley 2007) and in the third usual general hospital inpatient care (Gade 2008).

- In the two meditation studies there were multiple comparative arms (Downey 2009; Williams 2005). In one study the comparative groups were massage or friendly visits (Downey 2009). The friendly visits involved either spending time with patients (reading, talking, running errands) or alternatively they could provide respite or other assistance to the patient's caregivers. In the other study there were three comparative groups: massage only, combined meditation and massage, or usual care. Usual care involved comprehensive assessments from a multi-disciplinary healthcare team, including substance misuse treatment, mental health services, a buddy programme, a prayer group and chaplaincy (Williams 2005).

\section{Risk of bias in included studies}

All studies' findings were at a high risk of bias because of underreporting of key methodological processes. See Figure 1 and Figure 2.

Figure I. 'Risk of bias' graph: review authors' judgements about each risk of bias item presented as percentages across all included studies.

\begin{tabular}{|c|c|c|c|c|c|c|}
\hline \multicolumn{7}{|c|}{ Random sequence generation (selection bias) } \\
\hline \multicolumn{7}{|c|}{ Allocation concealment (selection bias) } \\
\hline \multicolumn{7}{|c|}{ Blinding (performance bias and detection bias) } \\
\hline \multicolumn{7}{|c|}{ Incomplete outcome data (attrition bias) } \\
\hline \multicolumn{7}{|c|}{ Selective reporting (reporting bias) } \\
\hline \multicolumn{7}{|c|}{ Other bias } \\
\hline & & $0 \%$ & $25 \%$ & $50 \%$ & $75 \%$ & $100 \%$ \\
\hline Low risk of bias & Unclear ris & of bias & & gh ris & & \\
\hline
\end{tabular}


Figure 2. 'Risk of bias' summary: review authors' judgements about each risk of bias item for each included study.

\begin{tabular}{|c|c|c|c|c|c|c|}
\hline & 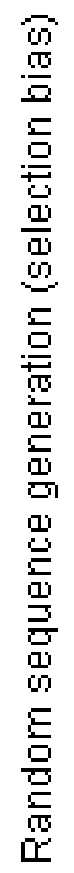 & 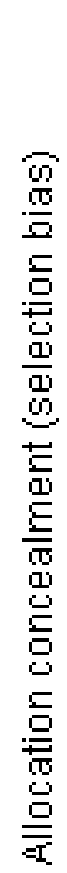 & 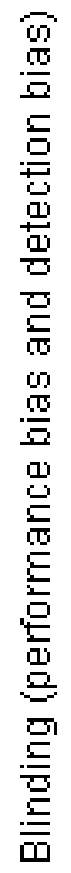 & 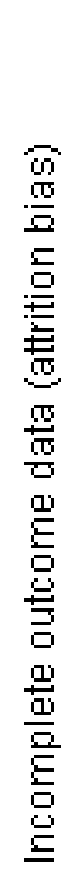 & 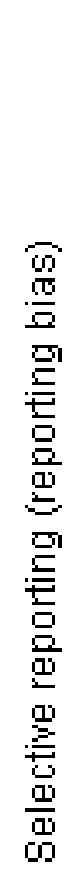 & 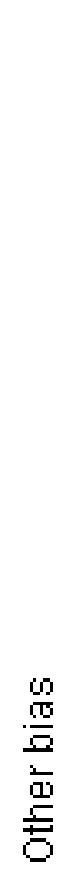 \\
\hline Brumley 2007 & 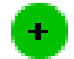 & $?$ & + & + & + & + \\
\hline Downey 2009 & $?$ & $?$ & $?$ & $?$ & & $?$ \\
\hline Gade 2008 & A & $?$ & $?$ & + & + & + \\
\hline Rabow 2004 & & & $?$ & & $?$ & $?$ \\
\hline Williams 2005 & + & $?$ & $?$ & + & $?$ & $?$ \\
\hline
\end{tabular}




\section{Randomisation}

Four studies provided adequate details on randomisation sequence generation (Brumley 2007; Gade 2008; Rabow 2004; Williams 2005).

\section{Allocation concealment}

None of the studies provided details on allocation concealment.

\section{Masked allocation}

Participants and providers of the intervention could not be masked to group allocation in these studies, but only one study stated that the research analyst was blind to group allocation (Brumley 2007).

\section{Attrition bias}

All studies reported the number of participants lost to follow-up. In two studies there was a risk of attrition bias as more than $25 \%$ of participants were lost; it is unclear in both studies whether any key demographic characteristics differed between drop-out groups (Rabow 2004; Williams 2005). Two studies used intention-totreat (ITT) analysis (Downey 2009; Williams 2005).

\section{Effects of interventions}

\section{Heterogeneity}

We did not pool trial effects, as studies were too heterogeneous in the nature of the intervention, the choice of outcome and how outcomes were measured. Although there were two studies in which choice of outcome and measures used both overlapped, they differed in the nature of the intervention: one involved an intervention composed of meditation only (Downey 2009) and the other was a multi-professional palliative intervention, which involved a chaplain as a core part of the team (Gade 2008). These studies also differed in their comparator groups: one compared the intervention with a person who provided home companionship activities (Downey 2009) and the other compared the intervention with usual care in a general hospital (Gade 2008).

\section{Comparison one: meditation or meditation with massage}

Two studies contributed to this analysis, in total they included 225 participants (Downey 2009; Williams 2005). They provide limited evidence on the review's primary outcomes. Only quality of life was assessed in both studies. In one study participants in the usual care group were encouraged to take up support services including a prayer group, the Chaplaincy service and religious services (Williams 2005). However, the number of participants doing so was not reported.

\section{Primary outcomes}

\section{Quality of life: meditation}

In one study in which data from 95 participants were analysed, there were no significant differences at nine weeks follow-up on quality of life (using a single item measure) between those receiving meditation and those receiving massage (mean difference (MD) 11.51; $95 \%$ confidence interval (CI) -24.23 to 1.21 ) or friendly visits (MD -1.63; 95\% CI -14.04 to 10.78) (Downey 2009). In the second study of 58 participants there were no significant differences in mean change from baseline to follow-up in quality of life (using the Missoula-VITAS Quality of Life Index) between the meditation and usual care groups (at eight weeks MD 0.38; $95 \%$ CI -2.67 to 3.43 , at 68 weeks MD 0.55 ; 95\% CI -3.67 to 4.77 (Williams 2005)). In an analysis of a subscale of their quality of life measure there were no significant differences in personal relationships (at eight weeks MD -9.81; 95\% CI -26.43 to 6.81 , and at 68 weeks MD $-6.77 ; 95 \% \mathrm{CI}-25.82$ to 12.28 ) and in physical functionality (at eight weeks MD 11.69; $95 \%$ CI -2.22 to 25.60 , and at 68 weeks MD 17.46; 95\% CI 1.27 to 33.65 ).

\section{Quality of life: meditation with massage}

In one study in the group that received both meditation and massage there was a significant difference in quality of life in the medium, but not in the longer term, favouring the combined intervention group compared with usual care (at eight weeks MD $4.31 ; 95 \%$ CI 1.33 to 7.29 , at 68 weeks MD 3.76; 95\% CI -0.35 to 7.87) (Williams 2005)). In the study's subscale analysis of their quality of life measure there were significant differences favouring the combined intervention group in physical functionality (at eight weeks MD 24.08; 95\% CI 10.24 to 37.92, at 68 weeks MD 22.15 ; $95 \%$ CI 6.89 to 37.41 , but not in personal relationships (at eight weeks MD 7.73; 95\% CI -9.66 to 25.12; at 68 weeks MD 5.38; $95 \%$ CI -13.74 to 24.50$)$.

\section{Well-being}

One study measured well-being in a subscale of their quality of life measure (Williams 2005). There were no significant differences between those who received the meditation intervention and those who received usual care (at eight weeks MD 5.94; 95\% CI -2.82 to 14.70 , and at 68 weeks MD $1.08,95 \%$ CI -9.81 to 11.97 ) or 
between those who received meditation and massage and those who received usual care (at eight weeks MD 1.18, 95\% CI -8.73 to 11.09 , and at 68 weeks MD $-2.15 ; 95 \%$ CI -14.48 to 10.18 ).

\section{Coping}

Assessments were not undertaken on coping with the disease process.

\section{Secondary outcomes}

\section{Physical symptoms}

Both studies assessed physical symptoms. In the Williams 2005 study there were no significant differences (in subscale analyses) in physical symptoms between the meditation group and the usual care group (at eight weeks MD $-4.53 ; 95 \% \mathrm{CI}-10.78$ to 1.72 , and at 68 weeks MD $-5.76 ; 95 \%$ CI -13.06 to 1.54) or between those who received meditation and massage and those who received usual care (at eight weeks MD 0.16; 95\% CI -5.98 to 6.30, and at 68 weeks MD 3.93; 95\% CI -5.14 to 13.00 ). In the Downey 2009 study there were no significant mean differences between those receiving friendly visits and those receiving meditation visits in the patient's reporting of their expected weeks of having low pain distress (adjusted MD from friendly visits in the meditation group +0.179 , SE 0.317 , P value 0.573 ).

\section{Transcendence}

In subscale analyses of the Missoula Vitas Quality of Life Index, one study assessed transcendence (Williams 2005). Transcendence as defined by the developer of the Quality of Life Index is the experience of connection with an enduring construct or the experience of meaning or purpose in life. The study found no significant difference between those in the meditation group and those in the usual care group (at eight weeks MD 0.51; 95\% CI -6.98 to 8.00, and at 68 weeks MD $-0.15 ; 95 \%$ CI -8.18 to 7.88 ). There was a significant difference, however, between those who received meditation and massage and those who received usual care (at eight weeks MD 10.05; 95\% CI 3.61 to 16.49 , and at 68 weeks 8.69; $95 \%$ CI 1.42 to 15.96 ).

\section{Other secondary outcomes}

Other secondary outcomes were not measured, including health service use, place of death and informal carer outcomes.

\section{Comparison two: multidisciplinary interventions involving the support of a chaplain versus usual care}

Three studies contributed to this analysis, in total they included 905 participants (Brumley 2007; Gade 2008; Rabow 2004). There was limited evidence on the review's primary outcomes; not all were evaluated and where they were evaluated they were not fully reported.

\section{Primary outcomes}

\section{Well-being}

Two studies assessed well-being (Gade 2008; Rabow 2004). In one they reported no significant difference between the trial arms in symptoms of depression or anxiety (complete data not provided) (Rabow 2004). In the other study they reported that those in the intervention group felt marginally more emotionally supported but this was not a significant difference (MD 0.30; 95\% CI 0.00 to 0.60 ) (Gade 2008).

\section{Quality of life}

Two studies assessed quality of life (Gade 2008; Rabow 2004). One reported no significant difference at follow-up between the trial arms (MD 0.10; 95\% CI -0.34 to 0.54 ) (Gade 2008). The other reported a significant difference (the data were not provided by the study authors) (Rabow 2004).

\section{Coping}

Assessments on coping with the disease process were not undertaken.

\section{Secondary outcomes}

Three studies measured secondary outcomes and findings were mixed.

\section{Physical symptoms}

Two studies evaluated physical symptoms (Gade 2008; Rabow 2004). In the Gade 2008 study they found no difference between trial groups in symptom severity (MD $-0.10 ; 95 \%$ CI -0.45 to $0.25)$. In the other study they found those in the intervention group were less likely to report dyspnoea (odds ratio (OR) 6.07; 95\% CI 1.04 to 35.56 ) and to have improved sleep quality (data not provided), but that there was no difference in the level of pain between the trial arms (data not provided) (Rabow 2004).

\section{Spiritual well-being}

In one study there was a significant difference favouring the intervention group in well-being relating to spiritual factors, such as connection, self actualisation and consonance (complete data not 
provided) (Rabow 2004). In another study they found no difference between participants in the trial arms in feeling spiritually supported (MD 0.40; 95\% CI -0.11 to 0.91) (Gade 2008).

\section{Health services use}

All three studies evaluated health service use (Brumley 2007; Gade 2008; Rabow 2004).

In one, significantly fewer participants in the intervention group had attended emergency departments (OR $0.51 ; 95 \%$ CI 0.30 to 0.87 ) or been admitted to hospital (36\% of those receiving the intervention compared to $59 \%$ receiving usual care, $\mathrm{P}$ value $<0.001$ ) (Brumley 2007). In the Rabow 2004 study there were significantly fewer visits to clinic by participants in the intervention group (MD -3.10; $95 \% \mathrm{CI}-5.79$ to -0.41 ) but no significance difference between trial arms in need for urgent care (MD -0.30; 95\% CI -0.61 to 0.01), hospital admissions (MD 0.4; 95\% CI 0.24 to 1.04 ), emergency department visits (MD $-0.10 ; 95 \% \mathrm{CI}$ -1.16 to 0.96 ), health specialist visits (MD $-2.10 ; 95 \%$ CI -5.7 to 1.50 ) or total hospital days (MD 2.00; 95\% CI -2.43 to 6.43). In the third study (Gade 2008) there was a trend in the intervention group towards fewer intensive care admissions (OR 0.52; 95\% CI 0.25 to 1.08$)$.

\section{Place of death}

The place of death was measured in the Brumley 2007 study, which reported that more participants in the intervention group died at home than those receiving usual care $(71 \%$ versus $51 \%, P$ value $<0.001)$.

\section{Informal carer outcomes}

Impact on the informal carer was not assessed.

\section{Other outcomes}

\section{Care satisfaction}

All three studies evaluated health care satisfaction (Brumley 2007; Gade 2008; Rabow 2004). Across the studies results were inconclusive.

In one they reported no significant difference in satisfaction with care (Rabow 2004). In another they reported that significantly more in the intervention group were satisfied at 30 and 90 days follow-up, but there was no significant difference at 60 days ( Brumley 2007). Complete data on this outcome were not provided in either study. In the third, both assessments of satisfaction used favoured those in the intervention arm (on care environment MD $0.40 ; 95 \%$ CI 0.16 to 0.64 , on care staff MD $0.60 ; 95 \%$ CI 0.27 to 0.93$)$ (Gade 2008).

\section{End of life preparation}

In one study more participants in the intervention group compared to those in the control group completed an advanced directive (91.1\% versus $77.8 \%$; P value 0.001 ) (Gade 2008).

In another study participants in the intervention group were more likely to have completed funeral arrangements (OR 9.60; 95\% CI 1.08 to 85.68 ), but there was no difference between trial arms in the proportion of participants who had completed a durable power of attorney or in making plans for the disposition of their possessions (Rabow 2004).

\section{Survival}

One study set out to assess survival: it found no difference between trial arms (Gade 2008). Another study reported differential survival between the two trial groups but this was not statistically significant (Brumley 2007).

\section{Cost of care}

All three studies evaluated the impact on healthcare costs (Brumley 2007; Gade 2008; Rabow 2004). None involved economic evaluations and so are limited in the evidence they provide. Also there was no consideration in the studies of uncertainty in the estimations, such as how different costs in different regions might affect results. In two studies the intervention was cheaper and more effective for the study outcome on patient satisfaction (Brumley 2007; Gade 2008). In the Rabow 2004 study there were improvements in spiritual well-being but these were not compared directly with costs.

\section{I S C U S S I O N}

\section{Summary of main results}

This review set out to consider the quality and outcomes of evidence on spiritual and religious interventions for adults in the terminal phase of a disease. The review identified five RCTs; all were undertaken in North American populations (Brumley 2007; Downey 2009; Gade 2008; Rabow 2004; Williams 2005). Trial participants mostly had a diagnosis of cancer, AIDS, lung or heart disease. Two types of interventions were evaluated: meditation (Downey 2009; Williams 2005) and multi-disciplinary palliative care interventions that offered the patient pastoral support from a chaplain or spiritual counsellor (Brumley 2007; Gade 2008; Rabow 2004).

The review was unable to answer the question of whether spiritual and religious interventions for adults in the terminal phase of a 
disease impact on patient outcomes. There was limited evidence on the review's primary outcomes of well-being and quality of life. There were no evaluations on impact of coping with the disease. Differences in analysis and under-reporting of results prevented consideration of any combined analysis. In the two studies of meditation interventions, individually there was no significant impact on overall quality of life or well-being (Downey 2009; Williams $2005)$. Although in one of these studies when meditation was provided with massage it was found to enhance medium-term quality of life (Williams 2005). For the multidisciplinary interventions that involved a chaplain or spiritual counsellor, in none of the evaluations on well-being and quality of life was there a significant difference between the trial arms (Brumley 2007; Gade 2008; Rabow 2004). Although there was a trend in one study towards those in the intervention group feeling more emotionally supported (Gade 2008). However, the evidence we found for interventions that involve a chaplain and those on meditation is weak (i.e. potentially biased) because of the limited number of participants and trials involved in this analysis. In addition there was variation in the components of each intervention and also in comparator. For instance, the multidisciplinary interventions differed by profession in terms of who was part of the team and while in four trials comparators were usual care, one involved an active control of friendly visits.

\section{Overall completeness and applicability of evidence}

The overall completeness of the evidence presented in this review is limited as few studies have been undertaken. No studies were identified of interventions involving prayer or yoga. Moreover, whilst we identified studies of interventions involving pastoral care from a religious leader the impact of this care may have been limited as it is unclear in the studies how much support per patient was provided by the trial chaplains.

The generalisability of our findings is also limited. None of the studies provided details on patients' religious or spiritual beliefs. The interventions were evaluated in a single cultural context, the United States, where religious affiliations and practice differ considerably from other countries. This difference may influence the relationship between spirituality and well-being.

\section{Quality of the evidence}

The studies (and this review) faced a number of difficulties. First, there are challenges in defining spirituality, which are reflected in the large number of terms we used to describe it in our search strategy. Even so, the terms we used may have been insufficient to capture all relevant interventions. We did not include terms to capture psychotherapeutic interventions that might impact on spiritual well-being, such as Dignity Therapy (Chochinov 2005) and Supportive Expressive Therapy (Classen 2001). We took this course because we wished to include only those interventions that had a specific, clearly defined spiritual component. Interventions which may indirectly affect spiritual well-being might be the subject of another review.

There is also no consensus on the exact nature of spiritual and religious needs and how they may vary between individuals during the disease process. Therefore not all interventions evaluated here may have been appropriate to all potential participants. There are also challenges in defining the terminal phase of a disease, in part as research on prognostic markers for all diseases is limited. To counter this we used two alternative criteria to define terminal phase: first that the patient had a progressive disease with a life expectancy of one year or less, or second that patients were receiving palliative care. However, because of difficulties in predicting prognosis, these interventions could not be evaluated in all groups for whom they might be relevant.

Our measures of effect were also problematic as the constructs of quality of life, well-being and coping in the terminal phase of a disease are under-explored. The measures used in the studies to assess such outcomes may be too non-specific to pick up real effects of such interventions. Moreover, whilst we selected our primary outcomes on the basis that they may be more sensitive to the potential effects of the intervention, not all our primary outcomes were measured in the studies; for example, none of the studies measured coping with the disease and in the Brumley 2007 study neither well-being nor quality of life were assessed.

There are also other limitations to our findings. The studies' findings were at a high risk of bias because of under-reporting of key methods. None of the studies fully reported their randomisation process. There was also a high risk of recruitment bias in one study, as more than $50 \%$ of those eligible declined to take part (Rabow 2004).

\section{A U T HORS' CONCLUSIONS}

\section{Implications for practice}

Whilst there is inconclusive evidence on the impact of spiritual or religious interventions on the emotional well-being of adults in the terminal phase of a disease this does not rule out the possibility that for some patients such interventions may provide benefit. In particular, because we identified few studies and of these some of the evaluated interventions were of a short duration and the spiritual or religious aspect of some of the trialled interventions may not have been provided to all participants.

It is not certain that addressing spiritual and religious issues will lead to improvements in the range of outcomes measured by studies in this review. Changes may occur in the less tangible aspects of existential experience that are much more difficult to measure. 
It seems likely that spiritual and religious experiences remain very personal. It is important therefore to continue to explore how they might be met to adopt a person-centred approach both to tailoring any intervention to individual need and making sure that it is available at appropriate times. Moreover, assessment tools alone may not be the best method to assess need in this area of care. Rather, need may be identified as a result of an interpersonal exploration in a non-judgemental and facilitating approach.

Our review provides little evidence to guide decision makers on whether, or which, spiritual interventions are effective in patients with cancer. Thus, given the current emphasis on the availability of spiritual care near the end of life, health providers will need to rely on common sense and might therefore restrict interventions to well-recognised forms such as pastoral care from religious leaders or various forms of meditation. This will also depend on the context and setting. In hospices which emphasise religious beliefs and values, provision of such care is appropriate. However in secular systems such as the UK's National Health Service (NHS), such provision must compete with other evidence-based treatments such as psychological therapy. Thus, if spiritual care is to continue to be recommended, there is an urgent need for evidence of its efficacy.

\section{Implications for research}

NICE guidance on supportive and palliative care for adults (2004) and the UK End of Life Care Strategy (2008) both make specific reference to increasing knowledge about how best to provide spiritual support for those with deteriorating health who face death. However, it remains unclear how this might best be achieved or how interventions should be designed to meet spiritual need and how their effectiveness could be evaluated.

The lack of clear theoretical underpinnings for the interventions included in this review poses a major problem, not just for us as review authors but also for policy makers. In order to recommend treatments policy makers need to know how, as well as whether, treatments work. If spiritual treatments are to be recommended in secular settings, then their place and relevance need to be established. Although there is an emphasis in modern health services on so-called holistic care, the secular nature of health services means that the need or desire for such care on the part of patients and their families cannot be assumed. Thus, here we not only need evidence of effectiveness of spiritual and religious treatments but we also require data on their acceptability, the populations in which they are effective, exactly how they are effective and how they should be delivered.

Our review gives little guidance on what an effective intervention might look like. None of the interventions were theory-based. Nor did any (as far as we know) have a clear theological base. We suggest, therefore, that future trials should evaluate interventions in which the spiritual or religious component(s): 1) are clearly delineated in plain language so that they can be reproduced in other settings; 2) have a clear theoretical base or theological underpinning; and 3) are delivered by appropriately trained people who follow guidelines, understand the aim of the intervention and restrain from emphasising their own beliefs. Furthermore, outcomes must be clearly described in both spiritual and secular terms and relate closely to the aims of the intervention. Future research should also include other types of spiritual and religious interventions not identified in this review, including prayer, provision of pastoral care from a religious leader which is not part of a multidisciplinary intervention, and yoga.

At the same time, the content of future interventions should be informed by recipient preferences, therefore drawing on evidence from pilot and feasibility research, perhaps incorporating a range or menu of possible approaches or components that could then be tailored to individual need or demand, assessing which of these key components is most effective in which types of population, e.g. older or younger patients for whom cultural norms differ, or those with different disease types, health profiles and symptom burdens. Due to the complexity of the healthcare states of participants, interventions for palliative care populations are usually multi-component and of high complexity. Research in populations other than North Americans is also needed. This is of particular importance in considering interventions with spiritual or religious components as North American culture is largely based on strong Judeo-Christian traditions. Evaluations also need to be direct comparisons of standard care versus identical standard care with an enhanced religious/spiritual component.

Intervention evidence is likely to arise from randomised trials but the nature of outcomes may differ. Thus, well-validated measures of spiritual coping, belief and well-being should be recognised as valid measures alongside other more familiar measures of physical and psychological health, general well-being and quality of life. Moreover, although going beyond the evidence generated in this review, there is a need to further develop and test measures on well-being and other outcomes that are optimal for the context of life/living at the terminal phase of a disease. Future trials should fully report key design features.

\section{ACKNOWLEDGEMENTS}

Marie Curie Cancer Care funded this review. We thank Jeff Round for commenting on the studies that involved cost evaluations. We would also like to thank Jessica Thomas and Caroline Struthers of the Cochrane Pain, Palliative and Supportive Review Group. We would also like to thank the authors who responded to our requests for further information; Lois Downey, David Katz and Paula Diehr. 


\section{R E F E R E N C E S}

\section{References to studies included in this review}

Brumley 2007 \{published data only\}

Brumley R, Enguidanos S, Jamison P, Seitz R, Morgenstern

$\mathrm{N}$, et al.Increased satisfaction with care and lower costs: results of a randomised trial of in-home palliative care. Journal of the American Geriatrics Society 2007;55: 993-1000.

Downey 2009 \{published data only\}

* Downey L, Diehr P, Standish LJ, Patrick DL, Kozak L Fisher D. Might massage or guided meditation provide 'means to a better end'? Primary outcomes from an efficacy trial with patients at the end of life. Journal of Palliative Care 2009;25:100-8.

Downey L, Engelberg RA, Standish LJ, Kozak L, Lafferty WE. Three lessons from a randomised trial of massage and meditation at end of life: patient benefit, outcome measure selection, and design of trials with terminally ill patients. American Journal of Hospice and Palliative Medicine 2009; 26:246-53.

Gade 2008 \{published data only\}

Gade G, Venohr I, Conner D, McGrady K, Beane J, Richardson RH. Impact of an inpatient palliative care team: a randomised controlled trial. Journal of Palliative Medicine 2008;11:180-9.

Rabow 2004 \{published data only\}

Rabow MW, Dibble SL, Pantilat SZ, McPhee SJ. The Comprehensive Care Team: a controlled trial of outpatient palliative medicine consultation. Archives of Internal Medicine 2004;164:83-91.

Williams 2005 \{published data only\}

Williams AL, Selwyn PA, Liberti L, Molde S, Njike VY, McCorkle R, et al.A randomised controlled trial of meditation and massage effects on quality of life in people with late-stage disease: a pilot study. Journal of Palliative Medicine 2005;8:939-52.

\section{References to studies excluded from this review}

Adachi 1990 \{published data only\}

Adachi I. Supporting therapy with Shi Quan Da Bu Tang in advanced breast cancer patients. Biomedical Research 1990; 11:25-31.

Bormann 2006 \{published data only\}

Bormann JL, Gifford AL, Shively M, Smith TL, Redwine L, Kelly A, et al.Effects of spiritual mantram repetition on HIV outcomes: a randomised controlled trial. Journal of Behavioural Medicine 2006;29:359-76.

Garland 2007 \{published data only\}

Garland SN, Carlson LE, Cook S, Lansdell L, Speca M. A non-randomized comparison of mindfulness-based stress reduction and healing arts programs for facilitating posttraumatic growth and spirituality in cancer outpatients. Supportive Care in Cancer 2007;15:949-61.
Park 2008 \{published data only\}

Park JH. Look beyond and rejoice: a spiritual intervention for patients with life threatening illness or chronic pain. Dissertation in partial fulfilment of the requirements for the degree of Doctor of Public Health in Health Education: Loma Linda University, USA 2008.

Pohl 2007 \{published data only\} Pohl G, Seemann H, Zojer N, Ochsner C, Luhan C, Schemper M, et al. "Laying on of hands" improves wellbeing in patients with advanced cancer. Supportive Care in Cancer 2007; 15:143-51.

Rummans 2006 \{published data only\} Rummans TA, Clark MM, Sloan JA, Frost MH, Bostwick JM, Atherton PJ, et al.Impacting quality of life for patients with advanced cancer with a structured multidisciplinary intervention: a randomised controlled trial. Journal of Clinical Oncology 2006;24:635-41.

Smith 2008 \{published data only\}

Smith LG. Prayer as an intervention for agitated dementia residents. Dissertation: University of New Mexico, USA 2008.

Wiesendanger 2001 \{published data only\}

Wiesendanger H, Werthmuller L, Reuter K, Walach H. Chronically ill patients treated by spiritual healing improve in quality of life: results of a randomized waiting list controlled study. Journal of Alternative and Complimentary Medicine 2001;7:45-51.

\section{Additional references}

Balboni 2007

Balboni TA, Vanderwerker LC, Block SD, Paulk E, Lathan CS, Peteet JR, et al.Religiousness and spiritual support among advanced cancer patients and associations with end of life treatment preferences and quality of life. Journal of Clinical Oncology 2007;26:555-60.

\section{Cardella 2004}

Cardella LA, Friedlander ML. The relationship between religious coping and psychological distress in parents of children with cancer. Journal of Psychological Oncology 2004; 22:19-37.

Chochinov 2005

Chochinov HM, Hack T, Hassard T, Kristjanson LJ,

McClement S, Harlos M. Dignity Therapy: a novel

psychotherapeutic intervention for patients near the end of life. Journal of Clinical Oncology 2005;23:5520-5.

Classen 2001

Classen C, Koopman C, Miller E, DiMiceli S, Giese-Davis J, Fobaur P, et al.Supportive-expressive group therapy and distress in patients with metastatic breast cancer. Archives of General Psychiatry 2001;58:494-501.

\section{Curlin 2007}

Curlin FA, Sellergren SA, Lantos JD, Chin MH. Physicians' observations and interpretations of the influence of religion 
and spirituality on health. Archives of Internal Medicine 2007; 167:649-54.

Ellershaw 2003

Ellershaw J, Wilkinson S (eds). Care of the Dying: a Pathway to Excellence. Oxford: Oxford University Press, 2003.

\section{Feuerstein 2006}

Feuerstein G. Yoga and meditation. Moksha Journal 2006, issue 1.

\section{Hampton 2007}

Hampton DM, Hollis DE, Lloyd DA, Taylor J, McMillian SC. Spiritual needs of persons with advanced cancer. American Journal Hospital Palliative Care 2007;24:42-8.

\section{Hay 1987}

Hay D. Exploring Inner Space. Harmondsworth: Penguin, 1987.

Higgins 2011

Higgins JPT, Green S (editors). Cochrane Handbook for Systematic Reviews of Interventions. Chichester: John Wiley and Sons, 2011.

Hill 1999

Hill PC, Hood RW. Measures of religiosity. Birmingham, Alabama: Religious Education Press, 1999.

\section{Hill 2000}

Hill PC, Pargament KI, Hood RW, McCullough ME, Swyers JP, Larson DB, et al.Conceptualizing religion and spirituality: points of commonality, points of departure. Journal for the Theory of Social Behaviour 2000;30:51-77.

Juni 2001

Juni P, Altman DG, Egger M. Systematic reviews in health care: assessing the quality of controlled clinical trials. BMJ 2001;323:42-6.

\section{Kendler 2003}

Kendler KS, Liu X-Q, Gardner CO, McCullough ME, Larson D, Prescott CA. Dimensions of religiosity and their relationship to lifetime psychiatric and substance use disorders. American Journal of Psychiatry 2003;160: 496-503.

King 1999

King M, Speck P, Thomas A. Spiritual belief and outcome from illness. Social Science and Medicine 1999;48:1291-9.

King 2006

King M, Jones L, Barnes K, Low J, Walker C, Wilkinson $S$, et al.Measuring spiritual belief: development and standardisation of a Beliefs and Values Scale. Psychological Medicine 2006;36:417-26.

King 2009

King M, Koenig H. Conceptualising spirituality for medical research and health service provision. BMC Health Services Research 2009;9:116.

\section{Koenig 2001}

Koenig HG, McCullough ME, Larson DB. Handbook of Religion and Health. Oxford; New York: Oxford University Press, 2001.

\section{Larimore 2002}

Larimore WL, Parker M, Crowther M. Should clinicians incorporate positive spirituality into their practices? What does the evidence say?. Annals Behavioural Medicine 2002. 24:69-73.

\section{Larson 1998}

Larson DB, Swyers JP, McCullough ME, Rockville MD. Scientific Research on Spirituality and Health: A Consensus Report. National Institute for Healthcare Research, 1998.

\section{Lo 2002}

Lo B, Ruston D, Kates RM, Arnold RM, Cohen CB, FaberLangendoen $\mathrm{K}$, et al.Discussing religious and spiritual issues at the end of life. JAMA 2002;287:749-54.

\section{MacLean 2003}

MacLean CD, Susi B, Phifer N, Schultz L, Bynum D, Franco M. Patient preference for physician discussion and practice of spirituality. Journal of General Internal Medicine 2003;18:38-43.

\section{McClain 2003}

McClain CS, Rosenfeld B, Breltbart W. Effect of spiritual well-being on end-of-life despair in terminally-ill cancer patients. Lancet 2003;361:1603-7.

McCord 2004

McCord G, Gilchrist VJ, Grossman SD, King BD,

McCormick KF, Oprandi AM, et al.Discussing spirituality with patients: a rational and ethical approach. Annals of Family Medicine 2004;2:356-61.

Miller 2003

Miller WR, Thoresen CE. Spirituality, religion and health: an emerging research field. American Psychologist 2003;58: 24-35.

Murray 2004

Murray SA, Kendall M, Boyd K, Worth A, Beniton TF. Exploring the spiritual needs of people dying from lung cancer or heart failure: a prospective qualitative interview study of patients and their carers. Palliative Medicine 2004; 18:39-46.

\section{NICE 2004}

Improving supportive and palliative care for adults with cancer. National Institute for Clinical Excellence 2004.

\section{RevMan 2011}

The Nordic Cochrane Centre, The Cochrane Collaboration. Review Manager (RevMan). 5.1. Copenhagen: The Nordic Cochrane Centre, The Cochrane Collaboration, 2011.

\section{Sloan 2000}

Sloan RP, Bagiella E, VandeCreek L, Poulos P. Should physicians prescribe religious activities?. New England Journal of Medicine 2000;342:1913-6.

\section{Speck 1998}

Speck P. Spiritual issues in palliative care. Oxford Textbook of Palliative Medicine. Oxford: Oxford University Press, 1998.

Tarakeshwar 2006

Tarakeshwar N, Vanderwerker LC, Paulk E, Pearce MJ, Kasl SV, Prigerson HG. Religious coping is associated with the 
quality of life of patients with advanced cancer. Journal of Palliative Medicine 2006;9:646-57.

\section{Walsh 2002}

Walsh K, King M, Jones L, Tookman A, Blizard R.

Do spiritual beliefs affect outcome of bereavement: a

prospective cohort study. BMJ 2002;324:1551.

\section{Walter 1997}

Walter T. The ideology and organization of spiritual care:

three approaches. Palliative Medicine 1997;11:21-30.

* Indicates the major publication for the study 
CHARACTERISTICS OF STUDIES

\section{Characteristics of included studies [ordered by study ID]}

Brumley 2007

\begin{tabular}{|c|c|c|}
\hline Methods & \multicolumn{2}{|c|}{ Randomised controlled 2-armed trial } \\
\hline Participants & \multicolumn{2}{|c|}{$\begin{array}{l}\text { Homebound, terminally ill patients ( } \mathrm{N} 298 \text { ) in the USA with a prognosis of approxi- } \\
\text { mately } 1 \text { year or less to live plus one or more hospital or emergency department visits in } \\
\text { the previous } 12 \text { months. No details on religious or spiritual beliefs }\end{array}$} \\
\hline Interventions & \multicolumn{2}{|c|}{$\begin{array}{l}\text { Aim: to determine whether an in-home palliative care intervention for terminally ill } \\
\text { patients can improve patient satisfaction, reduce medical care costs, and increase the } \\
\text { proportion of patients dying at home } \\
\text { Interventionist: the core team consisted of the participant, family, physician, nurse and } \\
\text { social worker. Additional team members including a spiritual counsellor or chaplain, } \\
\text { bereavement co-ordinator, home health aide, pharmacist, dietitian, volunteer, physical } \\
\text { therapist, occupational therapist and speech therapist joined the core care team per } \\
\text { patient as their services were needed } \\
\text { Duration: until death } \\
\text { Intervention: in-home palliative care plus usual care delivered by an interdisciplinary } \\
\text { team providing pain and symptom relief, patient and family education and training, } \\
\text { and an array of medical and support services. Participants were assigned a palliative care } \\
\text { physician who co-ordinated care from a variety of healthcare providers. It is unclear how } \\
\text { many participants received spiritual support } \\
\text { Comparative treatment: usual care. These services included various amounts and levels of } \\
\text { home health services, acute care services, primary care services and hospital care }\end{array}$} \\
\hline Outcomes & \multicolumn{2}{|c|}{$\begin{array}{l}\text { Satisfaction with care } 30,60 \text { and } 90 \text { days after enrolment, use of medical services, site } \\
\text { of death and costs of care }\end{array}$} \\
\hline Notes & \multicolumn{2}{|c|}{ Sample size calculation met } \\
\hline \multicolumn{3}{|l|}{ Risk of bias } \\
\hline Bias & Authors' judgement & Support for judgement \\
\hline $\begin{array}{l}\text { Random sequence generation (selection } \\
\text { bias) }\end{array}$ & Low risk & $\begin{array}{l}\text { Group assignment was determined by block } \\
\text { randomisation using a computer-generated ran- } \\
\text { dom number chart stratified according to study } \\
\text { site }\end{array}$ \\
\hline Allocation concealment (selection bias) & Unclear risk & No details given \\
\hline $\begin{array}{l}\text { Blinding (performance bias and detection } \\
\text { bias) } \\
\text { All outcomes }\end{array}$ & Low risk & $\begin{array}{l}\text { Although blinding of carers and participants } \\
\text { was not possible, data were collected by re- } \\
\text { searchers blind to group assignments }\end{array}$ \\
\hline
\end{tabular}




\begin{tabular}{l|l|l}
\hline $\begin{array}{l}\text { Incomplete outcome data (attrition bias) } \\
\text { All outcomes }\end{array}$ & Low risk & $\begin{array}{l}5 \text { participants withdrew, 2 in intervention group } \\
\text { and 3 in control }\end{array}$ \\
\hline Selective reporting (reporting bias) & Low risk & $\begin{array}{l}\text { Protocol not available but all prespecified out- } \\
\text { comes were reported. For the satisfaction in care } \\
\text { outcome, demographic and illness variables at } \\
30,60 \text { and } 90 \text { days were not tested between } \\
\text { groups, especially since there was a reduction in } \\
\text { sample size }\end{array}$ \\
\hline Other bias & Low risk & $\begin{array}{l}\text { Differential survival was reported between the } \\
\text { 2groups but this was not statistically significant } \\
\text { and hence unlikely to be a source of bias }\end{array}$ \\
\hline
\end{tabular}

\section{Downey 2009}

\begin{tabular}{|c|c|}
\hline Methods & 3-armed randomised controlled trial \\
\hline Participants & $\begin{array}{l}167 \text { AIDS or stage IV cancer patients enrolled in the USA in a hospice or palliative } \\
\text { care programme with a survival prognosis between } 3 \text { weeks and } 6 \text { months. Aged over } \\
18 \text { years. At the time of enrolment each patient nominated a study partner who could } \\
\text { provide information at baseline and after their death. Most study partners were family } \\
\text { members or close friends. } 61 \% \text { of deceased patients and } 74 \% \text { of partners were female. } \\
\text { Median age of participants was } 74 \text { years (range } 36 \text { to } 98 \text { ) and partner } 54 \text { years (range } \\
22 \text { to } 87 \text { ). } 71 \% \text { of participants had cancer, } 14 \% \text { cardiovascular disease, } 6 \% \text { neurological } \\
\text { and } 6 \% \text { pulmonary. No details on religious or spiritual beliefs }\end{array}$ \\
\hline Interventions & $\begin{array}{l}\text { Aim: to investigate in end of life patients the effects of } 2 \text { therapies, massage and guided } \\
\text { meditation, on participants' overall quality of life and pain distress } \\
\text { Interventionist: meditation instructors were licensed naturopathic physicians and mas- } \\
\text { sage providers were licensed massage therapists. Friendly visitors were trained hospice } \\
\text { volunteers } \\
\text { Duration: up to } 2 \text { treatments a week, treatment continued until patient's death or vol- } \\
\text { untary withdrawal from study } \\
\text { Intervention: } 3 \text { treatment groups: } \\
\text { 1. Massage: light back and neck massage, followed by effleurage and goodbye } \\
\text { holding. Depending on the need, the massage therapist spent some time focusing on } \\
\text { areas of particular tension or stress. } \\
\text { 2. Meditation: meditation providers aimed to lead the patient into progressive } \\
\text { muscle relaxation, mindfulness-based meditation and guided imagery/visualisation } \\
\text { 3. Active control offriendly visits: friendly visitors spent the allotted time with } \\
\text { participants either reading to them, conversing with them, just spending time with } \\
\text { them, writing letters for them, doing light chores or running errands; or alternatively } \\
\text { they provided respite or other assistance to caregivers without directly interacting with } \\
\text { the participants } \\
\text { Treatment provided at participants location of choice - typically at home }\end{array}$ \\
\hline
\end{tabular}




\begin{tabular}{|c|c|c|}
\hline Outcomes & \multicolumn{2}{|c|}{$\begin{array}{l}\text { Participant and partner's quality of life using a single item rating of } 0 \text { to } 10 \text {, pain distress } \\
\text { which was measured using items from the Memorial Symptom Assessment Scale. Primary } \\
\text { outcome was participant's quality of life }\end{array}$} \\
\hline Notes & \multicolumn{2}{|l|}{ Power calculation met } \\
\hline \multicolumn{3}{|l|}{ Risk of bias } \\
\hline Bias & Authors' judgement & Support for judgement \\
\hline $\begin{array}{l}\text { Random sequence generation (selection } \\
\text { bias) }\end{array}$ & Unclear risk & No details provided \\
\hline Allocation concealment (selection bias) & Unclear risk & No details provided \\
\hline $\begin{array}{l}\text { Blinding (performance bias and detection } \\
\text { bias) } \\
\text { All outcomes }\end{array}$ & Unclear risk & No details provided \\
\hline $\begin{array}{l}\text { Incomplete outcome data (attrition bias) } \\
\text { All outcomes }\end{array}$ & Unclear risk & $\begin{array}{l}\text { No drop outs in massage group, } 4 \text { in friendly visit } \\
\text { intervention and } 4 \text { in meditation group, reasons } \\
\text { not provided. ITT analysis undertaken, no de- } \\
\text { tails on how this was undertaken }\end{array}$ \\
\hline Other bias & Unclear risk & Recruitment rate not stated \\
\hline
\end{tabular}

Gade 2008

\begin{tabular}{ll}
\hline Methods & Multicentre (3 sites) randomised controlled trial \\
\hline Participants & $\begin{array}{l}\text { US } 517 \text { adult patients hospitalised with a life-limiting illness and whose attending physi- } \\
\text { cian indicated that they 'would not be surprised if the patient died within a year'. Mean } \\
\text { age (SD) in intervention group } 73.6(12.6) \text { years and control group } 73.1 \text { (13.2) years. } \\
\text { No details on religious or spiritual beliefs }\end{array}$ \\
\hline Interventions & $\begin{array}{l}\text { Aim: to measure the impact of an interdisciplinary palliative care service on participant } \\
\text { satisfaction, clinical outcomes and cost of care for } 6 \text { months post hospital discharge } \\
\text { Interventionist: hospital in-patient palliative care team of a physician, nurse, hospital } \\
\text { social worker and chaplain } \\
\text { Duration: length of hospital stay } \\
\text { Intervention: the team provided palliative care. The team met with the participant/family } \\
\text { to address symptoms, diagnosis, prognosis and goals of care. Psychosocial and spiritual } \\
\text { concerns were identified and advanced directive forms discussed. They developed a care } \\
\text { plan and followed up the participant in hospital and at discharge } \\
\text { Comparative treatment: usual care in a general hospital }\end{array}$ \\
\hline
\end{tabular}




\begin{tabular}{|c|c|c|}
\hline Outcomes & \multicolumn{2}{|c|}{$\begin{array}{l}\text { Primary outcomes were symptom control, levels of emotional and spiritual support, pa- } \\
\text { tient satisfaction and total health service costs at } 6 \text { months post index hospitalisation. } \\
\text { Secondary measures were survival, number of advanced directives at discharge and hos- } \\
\text { pice utilisation within the } 6 \text { months in which study enrolment occurred }\end{array}$} \\
\hline \multicolumn{3}{|l|}{ Notes } \\
\hline \multicolumn{3}{|l|}{ Risk of bias } \\
\hline Bias & Authors' judgement & Support for judgement \\
\hline $\begin{array}{l}\text { Random sequence generation (selection } \\
\text { bias) }\end{array}$ & Low risk & $\begin{array}{l}\text { A computer-generated randomised assign- } \\
\text { ment list for each site was used for sequence } \\
\text { generation }\end{array}$ \\
\hline Allocation concealment (selection bias) & Unclear risk & $\begin{array}{l}\text { Details of whether participants and inves- } \\
\text { tigators could foresee assignment not given }\end{array}$ \\
\hline $\begin{array}{l}\text { Blinding (performance bias and detection } \\
\text { bias) } \\
\text { All outcomes }\end{array}$ & Unclear risk & $\begin{array}{l}\text { Not clear whether outcomes were evaluated } \\
\text { blindly }\end{array}$ \\
\hline $\begin{array}{l}\text { Incomplete outcome data (attrition bias) } \\
\text { All outcomes }\end{array}$ & Low risk & $\begin{array}{l}\text { Out of the } 517 \text { randomised } 5 \text { (0.01) with- } \\
\text { drew }\end{array}$ \\
\hline Selective reporting (reporting bias) & Low risk & All specified outcomes reported \\
\hline Other bias & Low risk & No other obvious source of bias \\
\hline
\end{tabular}

Rabow 2004

\begin{tabular}{ll}
\hline Methods & 2-armed randomised controlled trial \\
\hline Participants & $\begin{array}{l}90 \text { male and female }(\mathrm{n}=58) \text { adult participants in the USA with a diagnosis of cancer (n } \\
=30) \text {, advanced COPD }(\mathrm{n}=29) \text { or advanced CHF }(\mathrm{n}=31) \text {. Believed by physian to } \\
\text { have a life expectancy of } 1 \text { to } 5 \text { years and who are not yet ready for hospice care. Mean } \\
\text { age in intervention group } 67.9 \text { years (SD 13.9) and control group 69.4 years (SD 11.2) } \\
\text {. No details on religious or spiritual beliefs }\end{array}$ \\
\hline Interventions & $\begin{array}{l}\text { Aim: to compare physical, psychological, social and spiritual outcomes between partic- } \\
\text { ipants receiving a multifaceted outpatient palliative medicine consultation and patients } \\
\text { receiving usual primary care } \\
\text { Interventionist: a social worker, nurse, chaplain, pharmacist, psychologist, art therapist, } \\
\text { volunteer co-ordinator and 3 physicians } \\
\text { Duration: } 12 \text { months } \\
\text { Intervention: } \text { multifaceted outpatient palliative medicine consultation intervention called } \\
\text { Comprehensive Care Team (CCT) } \\
\text { The intervention had } 7 \text { components: }\end{array}$ \\
\hline
\end{tabular}




\begin{tabular}{|c|c|c|}
\hline & \multicolumn{2}{|c|}{$\begin{array}{l}\text { 1. The intervention team advised/provided recommendations following in-depth } \\
\text { patient assessment the primary care physician at } 3 \text { time points on physical symptoms, } \\
\text { psychological well-being, social support, spiritual well-being and advanced care } \\
\text { planning } \\
\text { 2. Social worker provided case management, to address advance care planning and } \\
\text { offered psychological support in person and on phone } \\
\text { 3. A nurse provided family caregiver training and support through formal classes and } \\
\text { informal individual consultation } \\
\text { 4. A pharmacist performed a medical chart review of the participant's medication } \\
\text { 5. A chaplain offered each participant spiritual and psychological support } \\
\text { 6. Participants and their families were invited to monthly support groups that } \\
\text { included discussions about symptom management and advance care planning } \\
\text { 7. Medical and pharmacy students provided volunteer patient support and advocacy } \\
\text { through weekly telephone contacts with patients, monthly visits and regular } \\
\text { communication } \\
\text { Comparative treatment: usual care involving attending a general medicine outpatient } \\
\text { clinic }\end{array}$} \\
\hline Outcomes & \multicolumn{2}{|c|}{$\begin{array}{l}\text { Functional status (using the Rapid Disability Rating Scale-2) and multiple study out- } \\
\text { comes, pain, sleep, anxiety (using Profile of Mood States), depression (Center for Epi- } \\
\text { demiological Studies Depression Scale), spiritual well-being (Spiritual Well Being Scale), } \\
\text { quality of life (Multidimensional Quality of Life Scale - Cancer version), health care sat- } \\
\text { isfaction (items from the Group Health Association of America Consumer Satisfaction } \\
\text { Survey) and advanced care planning (questionnaire devised for study). Medical record } \\
\text { data on health service use. Exit interview on satisfaction with intervention and its effects } \\
\text { on family and usual care }\end{array}$} \\
\hline \multicolumn{3}{|l|}{ Notes } \\
\hline \multicolumn{3}{|l|}{ Risk of bias } \\
\hline Bias & Authors' judgement & Support for judgement \\
\hline $\begin{array}{l}\text { Random sequence generation (selection } \\
\text { bias) }\end{array}$ & High risk & $\begin{array}{l}\text { States that on the basis of a coin flip, patients in } \\
\text { one clinic module were assigned to be the inter- } \\
\text { vention group and patients in the second mod- } \\
\text { ule assigned to the control group. Each partici- } \\
\text { pant's assignment to practice modules was based } \\
\text { on appointment and space available at the time } \\
\text { of enrolment }\end{array}$ \\
\hline Allocation concealment (selection bias) & High risk & $\begin{array}{l}\text { Physicians and participants were assigned to } 1 \text { of } \\
2 \text { practices }\end{array}$ \\
\hline $\begin{array}{l}\text { Blinding (performance bias and detection } \\
\text { bias) } \\
\text { All outcomes }\end{array}$ & Unclear risk & $\begin{array}{l}\text { Data were collected through surveys and survey } \\
\text { completion was supervised by member of staff }\end{array}$ \\
\hline
\end{tabular}




\begin{tabular}{l|l|l}
\hline $\begin{array}{l}\text { Incomplete outcome data (attrition bias) } \\
\text { All outcomes }\end{array}$ & Low risk & $\begin{array}{l}5 \text { intervention participants and } 4 \text { controls did } \\
\text { not complete the intervention (this does not in- } \\
\text { clude the 10 intervention participants and 5 con- } \\
\text { trols who died). Characteristics of participants } \\
\text { with incomplete data and those with complete } \\
\text { data were not compared }\end{array}$ \\
\hline Selective reporting (reporting bias) & Unclear risk & $\begin{array}{l}\text { Protocol not available but all specified outcomes } \\
\text { were reported }\end{array}$ \\
\hline Other bias & Unclear risk & $\begin{array}{l}\text { Power calculation made but not met was done } \\
\text { and sample size of 50 in each group was specified } \\
\text { but only 40 participants remained in the control } \\
\text { group } \\
57 \% \text { intervention and } 65 \% \text { in the control group } \\
\text { refused participation; the most common reason } \\
\text { was that they were too ill }\end{array}$ \\
\hline
\end{tabular}

\section{Williams 2005}

\begin{tabular}{|c|c|}
\hline Methods & $2 \times 2$ factorial randomised control pilot trial \\
\hline Participants & $\begin{array}{l}58 \text { male and female ( } \mathrm{n}=24) \text { patients in the USA with late-stage disease of either AIDS } \\
\text { or a comorbidity. Diagnosis of AIDS as defined by the CDC HIV classification system } \\
\text { and had been resident for at least a month (to allow for stabilisation of medications and } \\
\text { equilibration to the environment) at nursing facility dedicated to HIV care and had a } \\
\text { life expectancy of at least } 2 \text { months. In addition to assure advanced AIDS and/or severe } \\
\text { debilitating disease status, participants needed to have at least one of the following: } 1 \text { - } \\
\text { CD4 T cell count less than } 200 \text { cells } / \mathrm{mm}^{3} ; 2 \text {-viral load greater than } 100,000 \text { copies } \\
\text { per millilitre; } 3 \text {-comorbid diagnosis of cancer, cirrhosis/liver failure, severe HF; severe } \\
\text { COPD or end-stage renal failure. Religious denomination: not stated } \\
\text { Mean age in meditation group } 45.08 \text { years (SD 2.2), in massage group } 42.81 \text { years (SD } \\
\text { 2.2), in meditation and massage group } 47.31 \text { (SD 2.25) and in standard care group } 45 \text {. } \\
56 \text { (SD 2.24) }\end{array}$ \\
\hline Interventions & $\begin{array}{l}\text { Aim: to evaluate the effects of meditation and massage on QOL in people with acquired } \\
\text { immunodeficiency syndrome (AIDS) } \\
\text { Interventionist: meditation teacher } \\
\text { Intervention: } 4 \text { trial arms: } \\
\text { 1. Meditation only: participants assigned to meditation intervention received a 90- } \\
\text { minute introductory group class on the basic principles of Metta meditation conducted } \\
\text { by a meditation teacher with extensive training and experience in Metta. Participants } \\
\text { were given a cassette player and audiotape on } 15 \text {-minute meditation exercise. They } \\
\text { were instructed to: } \\
\text { 2. follow the exercise at least daily for } 4 \text { weeks. The teacher met briefly individually } \\
\text { each participant to answer any questions and inquire about the residents ability to } \\
\text { adopt the meditation practice. } \\
\text { 3. Massage only: } 30 \text {-minute Swedish massage } 5 \text { days per week. Residents were able to }\end{array}$ \\
\hline
\end{tabular}


Williams 2005 (Continued)

\begin{tabular}{|c|c|c|}
\hline & \multicolumn{2}{|c|}{$\begin{array}{l}\text { choose what body area was massaged. The massage therapist was instructed to refrain } \\
\text { from providing verbal affirmations. } \\
\text { 4. Combined meditation and massage } \\
\text { 5. Standard care } \\
\text { All residents received comprehensive assessments by a multidisciplinary healthcare team. } \\
\text { The unit provided substance abuse treatment, mental health services, buddy program, } \\
\text { reflexology, prayer group, Chaplaincy and recreation therapy } \\
\text { Duration: of interventions } 1 \text { month }\end{array}$} \\
\hline Outcomes & \multicolumn{2}{|c|}{$\begin{array}{l}\text { Changes on Missoula-Vitas QOL Index overall and transcendent (spiritual) scores at } 8 \\
\text { weeks }\end{array}$} \\
\hline \multicolumn{3}{|l|}{ Notes } \\
\hline \multicolumn{3}{|l|}{ Risk of bias } \\
\hline Bias & Authors' judgement & Support for judgement \\
\hline $\begin{array}{l}\text { Random sequence generation (selection } \\
\text { bias) }\end{array}$ & Low risk & $\begin{array}{l}\text { SAS version } 8.2 \text { assigned participants to } \\
\text { randomisation. Block randomisation was } \\
\text { used but the size of block or method of se- } \\
\text { quence generation not given }\end{array}$ \\
\hline Allocation concealment (selection bias) & Unclear risk & Details not given \\
\hline $\begin{array}{l}\text { Blinding (performance bias and detection } \\
\text { bias) } \\
\text { All outcomes }\end{array}$ & Unclear risk & $\begin{array}{l}\text { The research associate who administered } \\
\text { the MVQOLI questionnaire was blinded to } \\
\text { intervention assignment and had no other } \\
\text { contact with residents }\end{array}$ \\
\hline $\begin{array}{l}\text { Incomplete outcome data (attrition bias) } \\
\text { All outcomes }\end{array}$ & Low risk & $\begin{array}{l}17 / 58 \text { patients were lost to follow-up. At- } \\
\text { trition either as decline in mental status, } \\
\text { death or discharged. Missing longitudinal } \\
\text { values were replaced and carried forward } \\
\text { from the last recorded values for all partic- } \\
\text { ipants who were randomised }\end{array}$ \\
\hline Selective reporting (reporting bias) & Unclear risk & All specified outcomes reported \\
\hline Other bias & Unclear risk & $\begin{array}{l}\text { Sample size calculation met. Recruitment } \\
\text { rate } 58 / 60 \\
\text { Baseline demographic and clinical charac- } \\
\text { teristics of the } 4 \text { groups did not differ signif- } \\
\text { icantly, except for the presence of co-mor- } \\
\text { bid diagnoses. Participants with comorbid } \\
\text { diagnoses were over-represented among the } \\
\text { combined meditation and massage group. } \\
\text { The authors suggest that despite the exces- } \\
\text { sive burden of disease this group demon- }\end{array}$ \\
\hline
\end{tabular}


CDC: US Centers for Disease Control and Prevention; CHF: congestive heart failure; COPD: chronic obstructive pulmonary disease;

ITT: Intention-to-treat; MVQOLI: Missoula-Vitas QOL Index; QOL: quality of life; SD: standard deviation

\section{Characteristics of excluded studies [ordered by study ID]}

\begin{tabular}{ll}
\hline Study & Reason for exclusion \\
\hline Adachi 1990 & Intervention is a type of Chinese medicine \\
\hline Bormann 2006 & Patients were not reported to be in the terminal phase of a disease \\
\hline Garland 2007 & Patients were not reported to be in the terminal phase of a disease \\
\hline Park 2008 & Patients were not reported to be in the terminal phase of a disease \\
\hline Pohl 2007 & $\begin{array}{l}\text { Patient was not actively involved in the intervention. The objective of the trial was to assess whether an actor } \\
\text { is as effective as a person with self declared healing powers in the laying on of hands }\end{array}$ \\
\hline Rummans 2006 & Patients were not reported to be in the terminal phase of a disease \\
\hline Smith 2008 & Patients were not reported to be in the terminal phase of a disease \\
\hline Wiesendanger 2001 & Patients were not reported to be in the terminal phase of a disease \\
\hline
\end{tabular}


DATA AND ANALYSES

Comparison 1. Comparison one: Meditation

\section{Outcome or subgroup title}

No. of No. of studies participants

\section{Statistical method}

Effect size
1 Quality of life at 9 weeks; meditation versus massage

2 Quality of life at 9 weeks; meditation versus friendly visits

3 Quality of life at 8 weeks (mean change); meditation

4 Quality of life at 68 weeks (mean change); meditation

5 Interpersonal relationships at 8 weeks (mean change); meditation

6 Interpersonal relationships at 68 weeks (mean change); meditation

7 Physical function at 8 weeks (mean change); meditation

8 Physical function at 68 weeks (mean change); meditation

9 Quality of life at 8 weeks (mean change); meditation and massage

10 Quality of life at 68 weeks (mean change); meditation and massage

11 Physical function at 8 weeks (mean change); meditation and massage

12 Physical function at 68 weeks (mean change); meditation and massage

13 Interpersonal relationships at 8 weeks (mean change); meditation and massage

14 Interpersonal relationships at 68 weeks (mean change); meditation and massage

15 Well-being at 8 weeks (mean change); meditation

16 Well-being at 68 weeks (mean change); meditation

\begin{tabular}{|c|c|c|c|}
\hline 1 & 95 & Mean Difference (IV, Fixed, 95\% CI) & $\begin{array}{l}-11.51[-24.23,1 \\
21]\end{array}$ \\
\hline 1 & 95 & Mean Difference (IV, Fixed, 95\% CI) & $\begin{array}{l}-1.63[-14.04,10 . \\
78]\end{array}$ \\
\hline 1 & 29 & Mean Difference (IV, Fixed, 95\% CI) & $0.38[-2.67,3.43]$ \\
\hline 1 & 29 & Mean Difference (IV, Fixed, 95\% CI) & $0.55[-3.67,4.77]$ \\
\hline 1 & 29 & Mean Difference (IV, Fixed, 95\% CI) & $-9.81[-26.43,6.81]$ \\
\hline 1 & 29 & Mean Difference (IV, Fixed, 95\% CI) & $\begin{array}{l}-6.77[-25.82,12 . \\
28]\end{array}$ \\
\hline 1 & 29 & Mean Difference (IV, Fixed, 95\% CI) & $11.69[-2.22,25.60]$ \\
\hline 1 & 29 & Mean Difference (IV, Fixed, 95\% CI) & $17.46[1.27,33.65]$ \\
\hline 1 & 29 & Mean Difference (IV, Fixed, 95\% CI) & $4.31[1.33,7.29]$ \\
\hline 1 & 29 & Mean Difference (IV, Fixed, 95\% CI) & $3.76[-0.35,7.87]$ \\
\hline 1 & 29 & Mean Difference (IV, Fixed, 95\% CI) & $24.08[10.24,37.92]$ \\
\hline 1 & 29 & Mean Difference (IV, Fixed, 95\% CI) & $22.15[6.89,37.41]$ \\
\hline 1 & 29 & Mean Difference (IV, Fixed, 95\% CI) & $7.73[-9.66,25.12]$ \\
\hline 1 & 29 & Mean Difference (IV, Fixed, 95\% CI) & $5.38[-13.74,24.50]$ \\
\hline 1 & 29 & Mean Difference (IV, Fixed, 95\% CI) & $5.94[-2.82,14.70]$ \\
\hline 1 & 29 & Mean Difference (IV, Fixed, 95\% CI) & $1.08[-9.81,11.97]$ \\
\hline
\end{tabular}

Spiritual and religious interventions for well-being of adults in the terminal phase of disease (Review)

Copyright $\odot 2012$ The Cochrane Collaboration. Published by John Wiley \& Sons, Ltd. 
17 Well-being at 8 weeks (mean change); meditation and massage

18 Well-being at 68 weeks (mean change); meditation and massage

19 Physical symptoms at 8 weeks (mean change); meditation

20 Physical symptoms at 68 weeks (mean change); meditation

21 Physical symptoms 8 weeks (mean change); meditation and massage

22 Physical symptoms at 68 weeks (mean change); meditation and massage

23 Transcendence at 8 weeks (mean change); meditation

24 Transcendence at 68 weeks (mean change); meditation

25 Transcendence at 8 weeks (mean change); meditation and massage

26 Transcendence at 68 weeks (mean change); meditation and massage

Comparison 2. Comparison two: Multi-disciplinary interventions involving the support of a chaplain

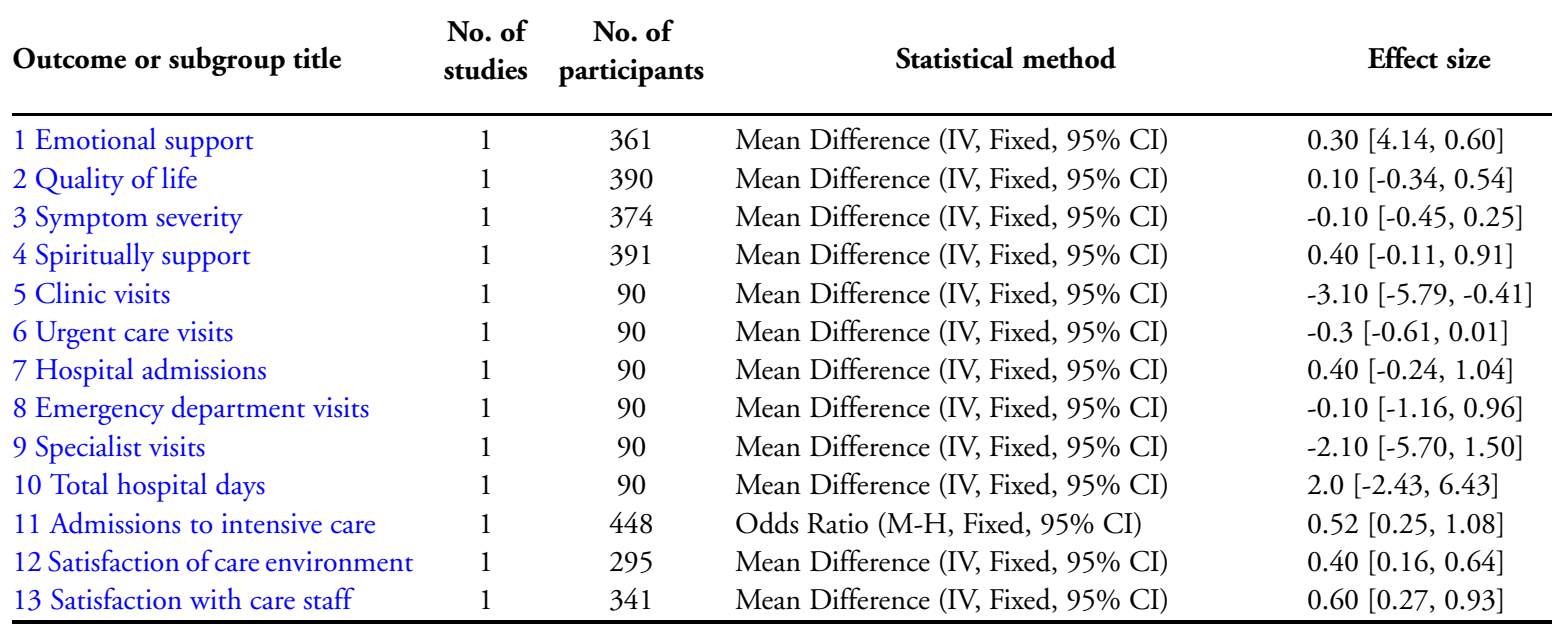


Analysis I.I. Comparison I Comparison one: Meditation, Outcome I Quality of life at 9 weeks; meditation versus massage.

Review: Spiritual and religious interventions for well-being of adults in the terminal phase of disease

Comparison: I Comparison one: Meditation

Outcome: I Quality of life at 9 weeks; meditation versus massage

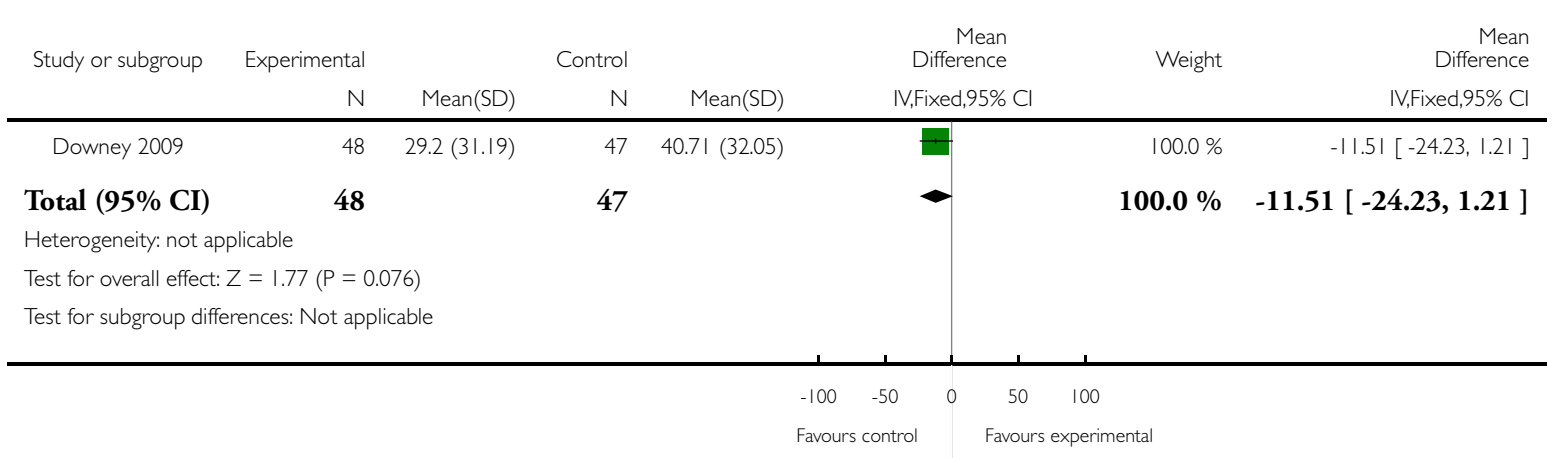

Analysis I.2. Comparison I Comparison one: Meditation, Outcome 2 Quality of life at 9 weeks; meditation versus friendly visits.

Review: Spiritual and religious interventions for well-being of adults in the terminal phase of disease

Comparison: I Comparison one: Meditation

Outcome: 2 Quality of life at 9 weeks; meditation versus friendly visits

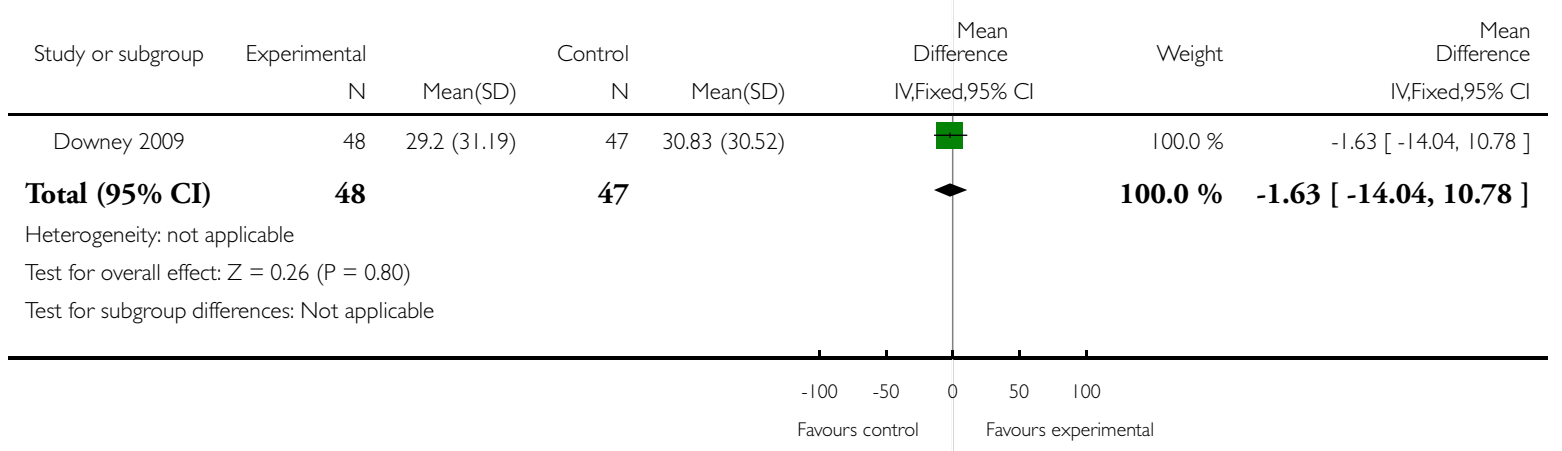


Analysis I.3. Comparison I Comparison one: Meditation, Outcome 3 Quality of life at 8 weeks (mean change); meditation.

Review: Spiritual and religious interventions for well-being of adults in the terminal phase of disease

Comparison: I Comparison one: Meditation

Outcome: 3 Quality of life at 8 weeks (mean change); meditation

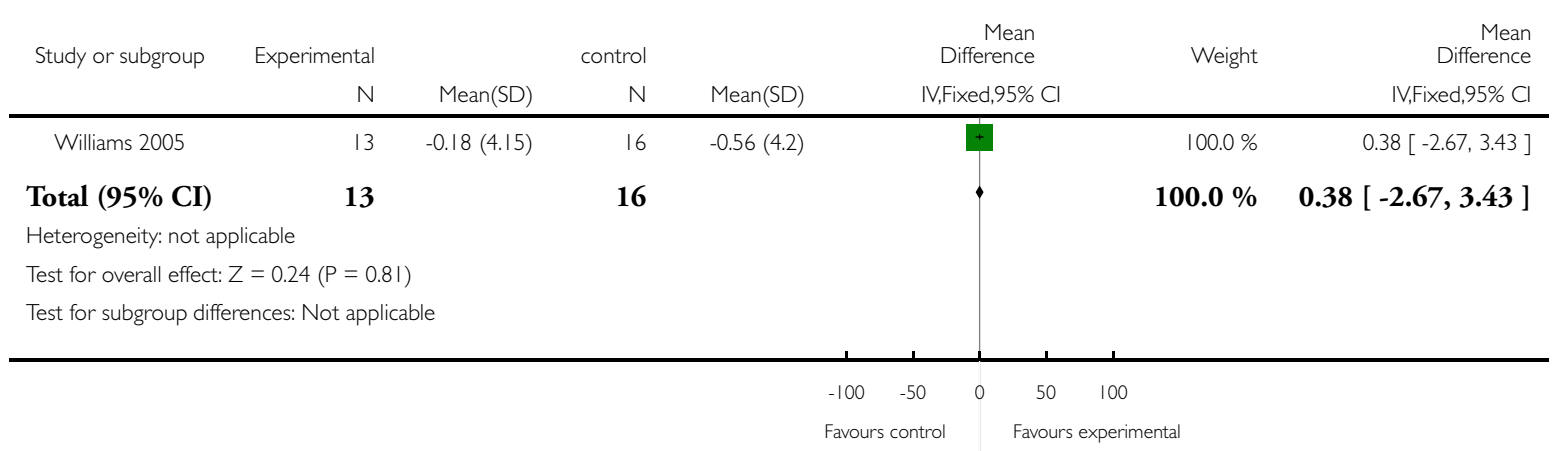

Analysis I.4. Comparison I Comparison one: Meditation, Outcome 4 Quality of life at 68 weeks (mean change); meditation.

Review: Spiritual and religious interventions for well-being of adults in the terminal phase of disease

Comparison: I Comparison one: Meditation

Outcome: 4 Quality of life at 68 weeks (mean change); meditation

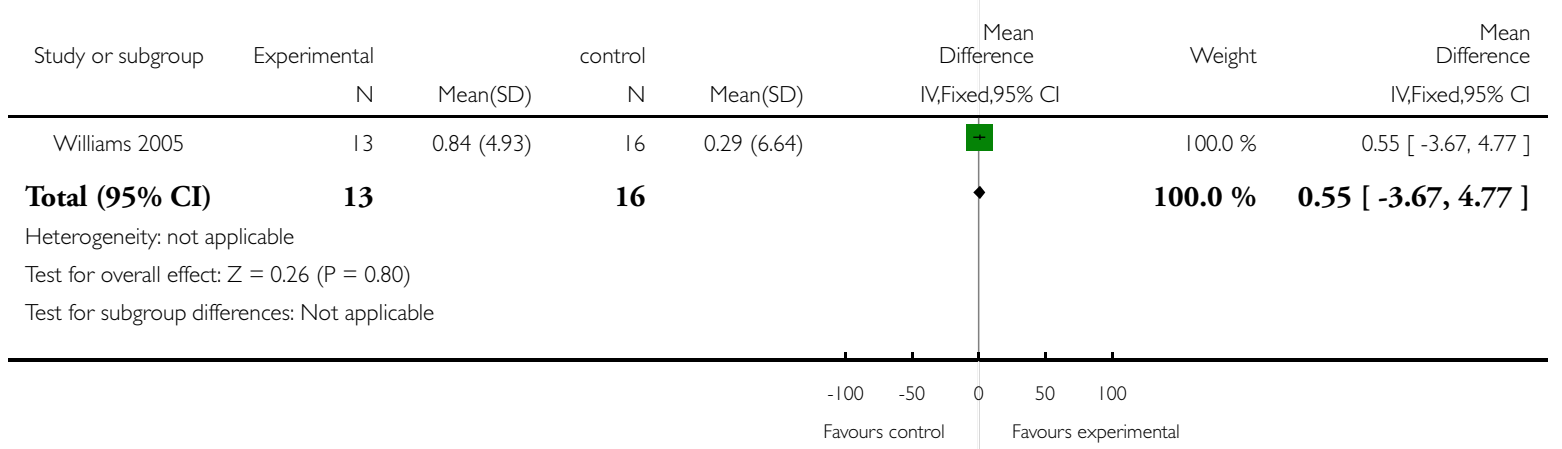


Analysis 1.5. Comparison I Comparison one: Meditation, Outcome 5 Interpersonal relationships at 8 weeks (mean change); meditation.

Review: Spiritual and religious interventions for well-being of adults in the terminal phase of disease

Comparison: I Comparison one: Meditation

Outcome: 5 Interpersonal relationships at 8 weeks (mean change); meditation

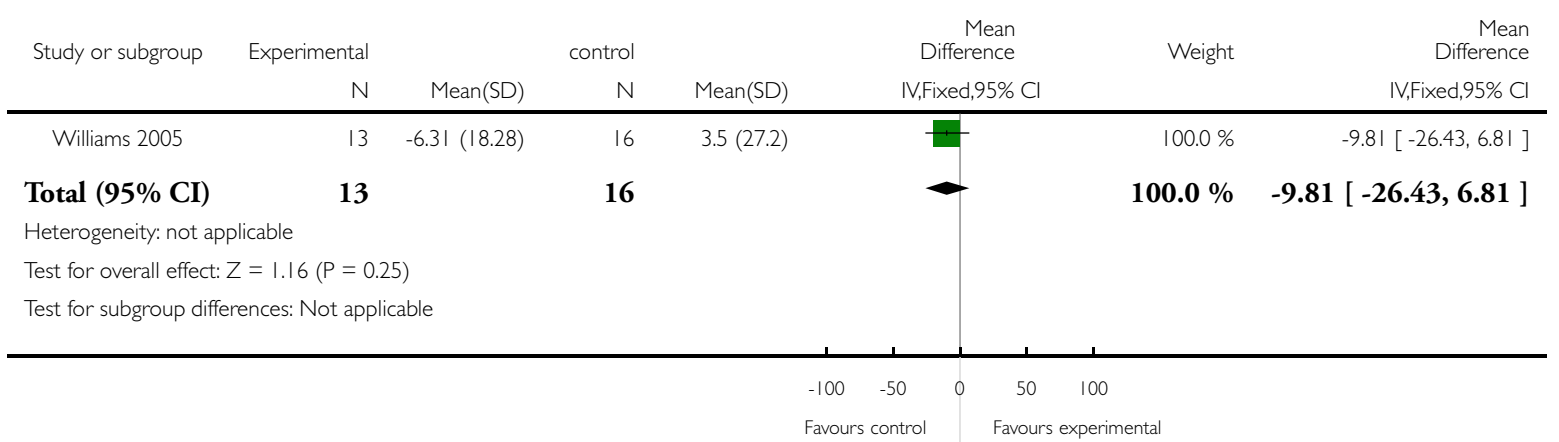

Analysis I.6. Comparison I Comparison one: Meditation, Outcome 6 Interpersonal relationships at 68 weeks (mean change); meditation.

Review: Spiritual and religious interventions for well-being of adults in the terminal phase of disease

Comparison: I Comparison one: Meditation

Outcome: 6 Interpersonal relationships at 68 weeks (mean change); meditation

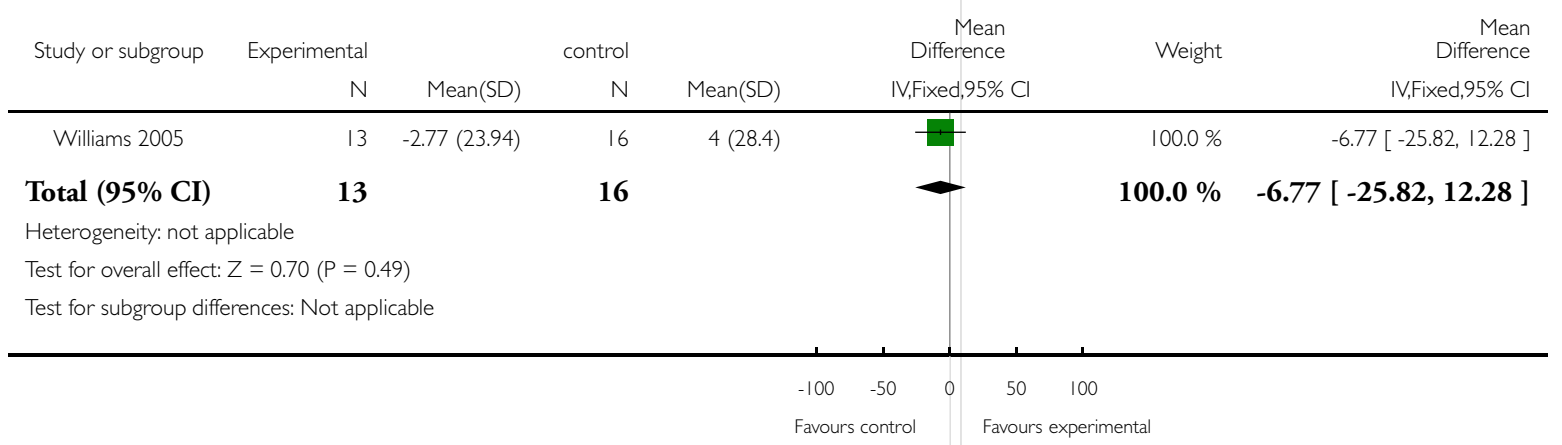


Analysis I.7. Comparison I Comparison one: Meditation, Outcome 7 Physical function at 8 weeks (mean change); meditation.

Review: Spiritual and religious interventions for well-being of adults in the terminal phase of disease

Comparison: I Comparison one: Meditation

Outcome: 7 Physical function at 8 weeks (mean change); meditation

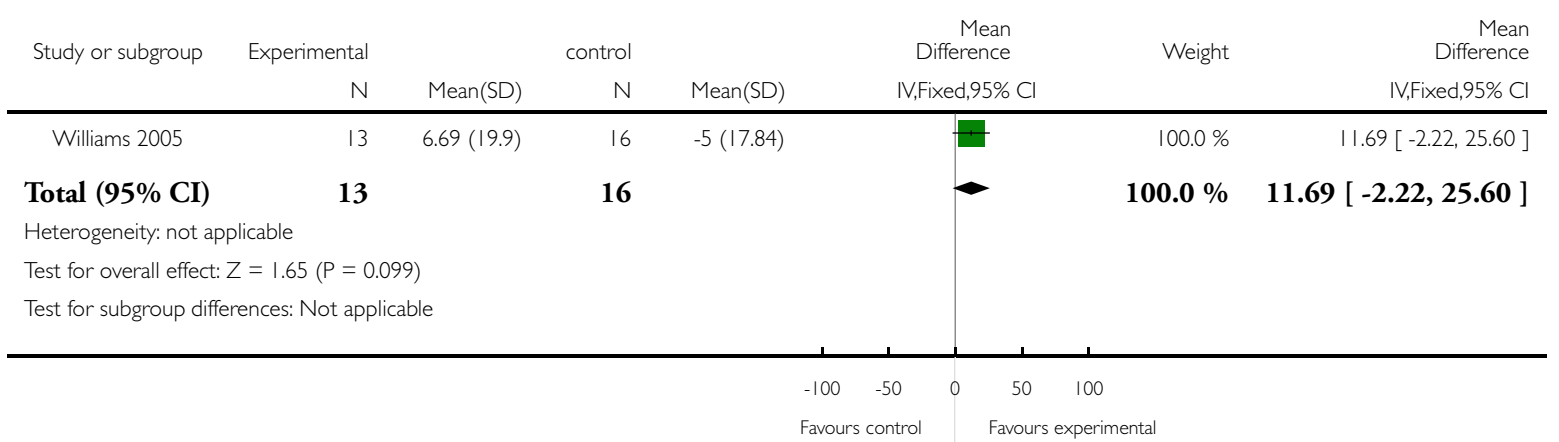

Analysis I.8. Comparison I Comparison one: Meditation, Outcome 8 Physical function at 68 weeks (mean change); meditation.

Review: Spiritual and religious interventions for well-being of adults in the terminal phase of disease

Comparison: I Comparison one: Meditation

Outcome: 8 Physical function at 68 weeks (mean change); meditation

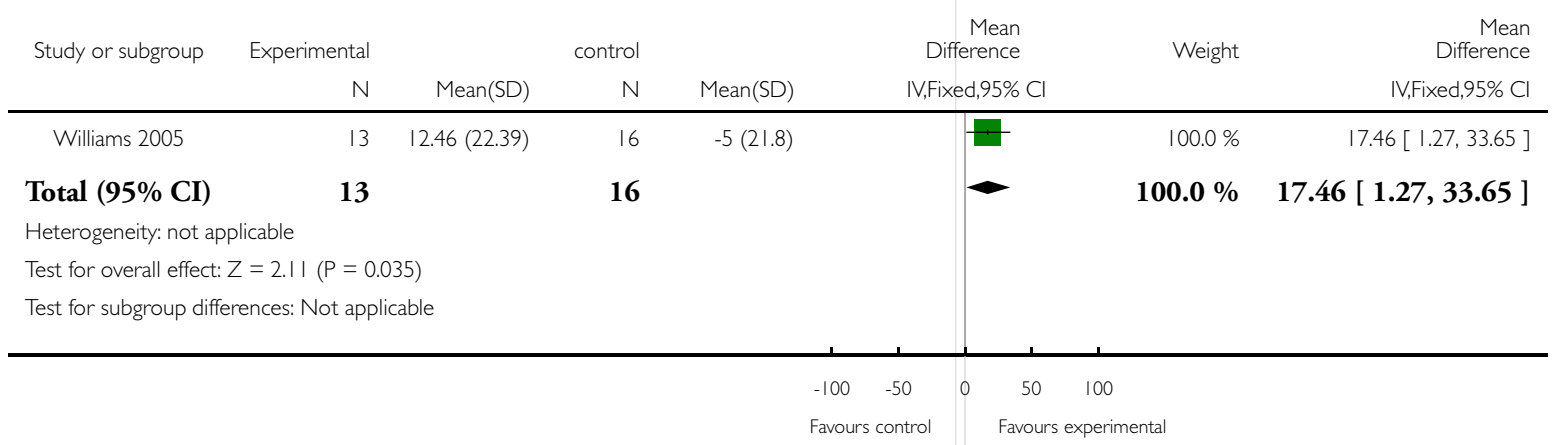


Analysis I.9. Comparison I Comparison one: Meditation, Outcome 9 Quality of life at 8 weeks (mean change); meditation and massage.

Review: Spiritual and religious interventions for well-being of adults in the terminal phase of disease

Comparison: I Comparison one: Meditation

Outcome: 9 Quality of life at 8 weeks (mean change); meditation and massage

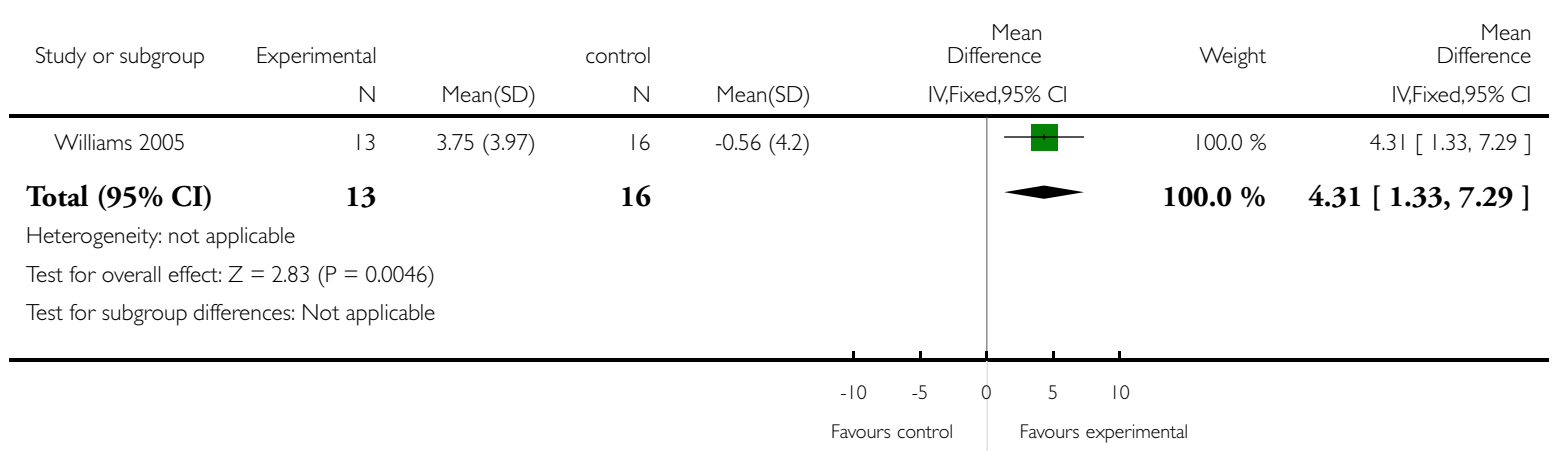

Analysis I.10. Comparison I Comparison one: Meditation, Outcome 10 Quality of life at 68 weeks (mean change); meditation and massage.

Review: Spiritual and religious interventions for well-being of adults in the terminal phase of disease

Comparison: I Comparison one: Meditation

Outcome: 10 Quality of life at 68 weeks (mean change); meditation and massage

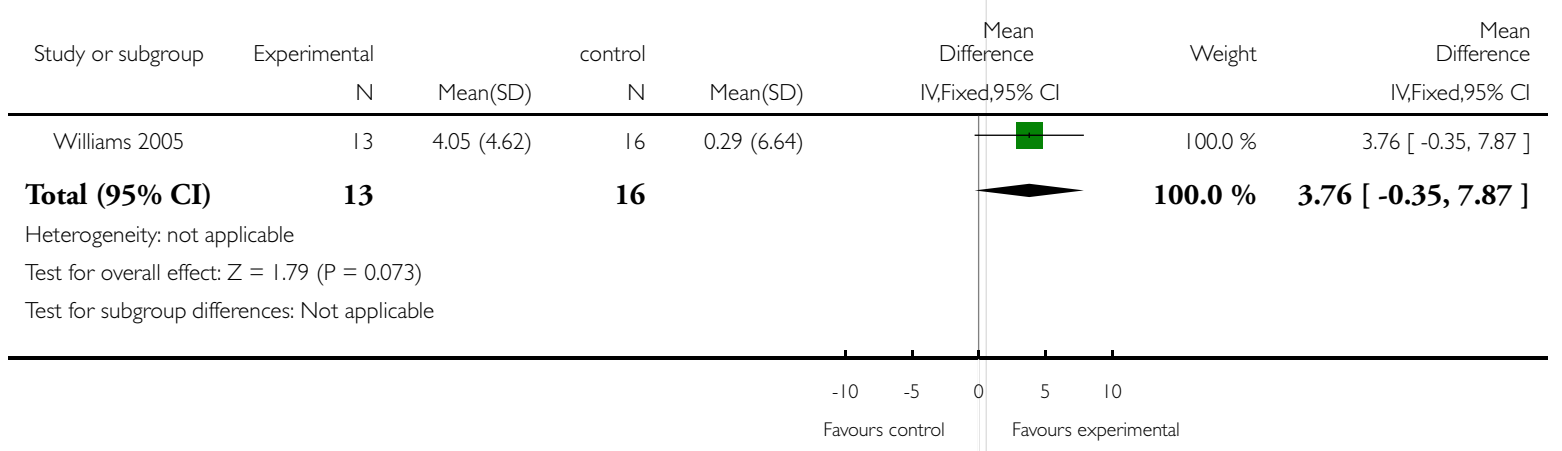


Analysis I.I I. Comparison I Comparison one: Meditation, Outcome I I Physical function at 8 weeks (mean change); meditation and massage.

Review: Spiritual and religious interventions for well-being of adults in the terminal phase of disease

Comparison: I Comparison one: Meditation

Outcome: II Physical function at 8 weeks (mean change); meditation and massage

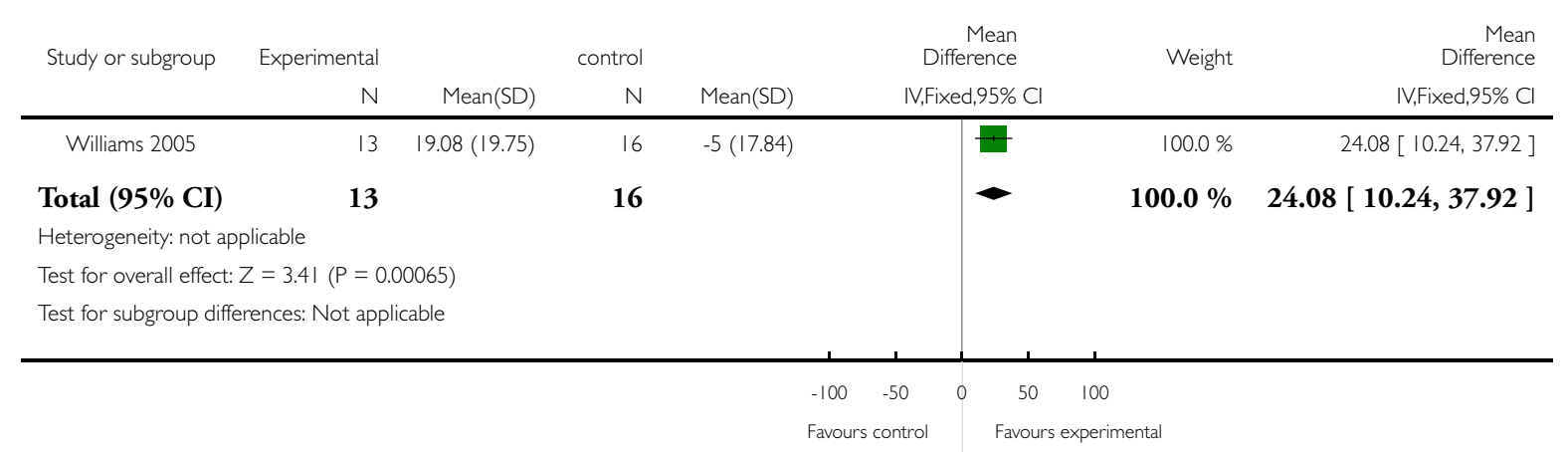

Analysis I.12. Comparison I Comparison one: Meditation, Outcome 12 Physical function at 68 weeks (mean change); meditation and massage.

Review: Spiritual and religious interventions for well-being of adults in the terminal phase of disease

Comparison: I Comparison one: Meditation

Outcome: 12 Physical function at 68 weeks (mean change); meditation and massage

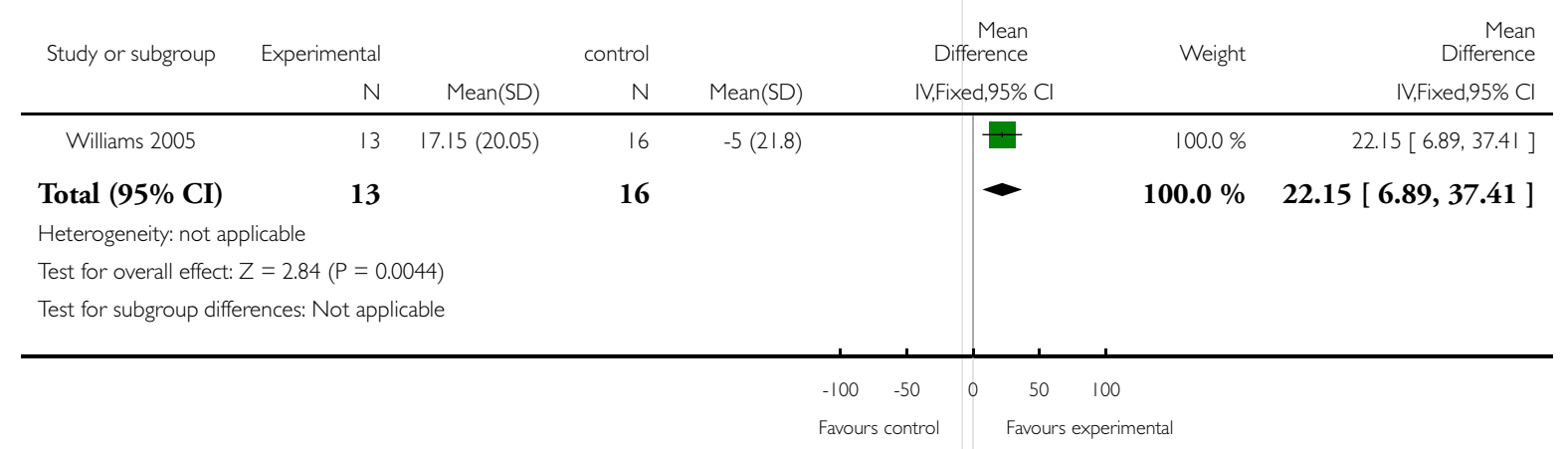


Analysis I.13. Comparison I Comparison one: Meditation, Outcome 13 Interpersonal relationships at 8 weeks (mean change); meditation and massage.

Review: Spiritual and religious interventions for well-being of adults in the terminal phase of disease

Comparison: I Comparison one: Meditation

Outcome: 13 Interpersonal relationships at 8 weeks (mean change); meditation and massage

\begin{tabular}{|c|c|c|c|c|c|c|c|c|}
\hline Study or subgroup & Experimental & \multicolumn{2}{|c|}{ control } & \multicolumn{3}{|r|}{$\begin{array}{r}\text { Mean } \\
\text { Difference }\end{array}$} & Weight & $\begin{array}{r}\text { Mean } \\
\text { Difference } \\
\text { IV,Fixed,95\% Cl }\end{array}$ \\
\hline Williams 2005 & 13 & I $1.23(20.56)$ & 16 & $3.5(27.2)$ & & 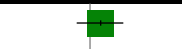 & $100.0 \%$ & $7.73[-9.66,25.12]$ \\
\hline Total $(95 \%$ CI $)$ & 13 & & 16 & & & $>$ & $100.0 \%$ & $7.73[-9.66,25.12]$ \\
\hline \multicolumn{9}{|c|}{ Heterogeneity: not applicable } \\
\hline & & & & & -100 & -50 & 100 & \\
\hline
\end{tabular}

Analysis I.I4. Comparison I Comparison one: Meditation, Outcome I4 Interpersonal relationships at 68 weeks (mean change); meditation and massage.

Review: Spiritual and religious interventions for well-being of adults in the terminal phase of disease

Comparison: I Comparison one: Meditation

Outcome: 14 Interpersonal relationships at 68 weeks (mean change); meditation and massage

\begin{tabular}{|c|c|c|c|c|c|c|c|c|}
\hline Study or subgroup & Experimental & \multicolumn{2}{|r|}{ control } & \multicolumn{3}{|r|}{$\begin{array}{r}\text { Mean } \\
\text { Difference }\end{array}$} & Weight & $\begin{array}{r}\text { Mean } \\
\text { Difference } \\
\text { IV,Fixed,95\% Cl }\end{array}$ \\
\hline Williams 2005 & 13 & $9.38(24.12)$ & 16 & $4(28.4)$ & & - & $100.0 \%$ & $5.38[-13.74,24.50]$ \\
\hline Total $(95 \% \mathrm{CI})$ & 13 & & 16 & & & 4 & $100.0 \%$ & $5.38[-13.74,24.50]$ \\
\hline \multicolumn{9}{|c|}{ Heterogeneity: not applicable } \\
\hline & & & & & -100 & -50 & 100 & \\
\hline & & & & & Favour & Favour & perimental & \\
\hline
\end{tabular}


Analysis I.15. Comparison I Comparison one: Meditation, Outcome 15 Well-being at 8 weeks (mean change); meditation.

Review: Spiritual and religious interventions for well-being of adults in the terminal phase of disease

Comparison: I Comparison one: Meditation

Outcome: 15 Well-being at 8 weeks (mean change); meditation

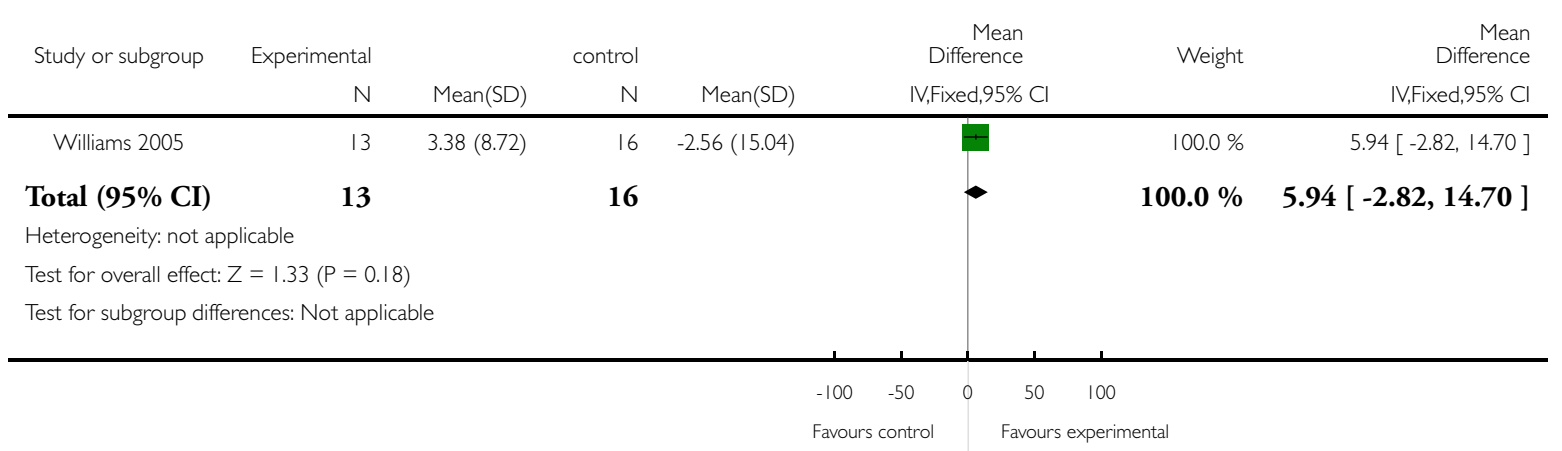

Analysis I.16. Comparison I Comparison one: Meditation, Outcome 16 Well-being at 68 weeks (mean change); meditation.

Review: Spiritual and religious interventions for well-being of adults in the terminal phase of disease

Comparison: I Comparison one: Meditation

Outcome: 16 Well-being at 68 weeks (mean change); meditation

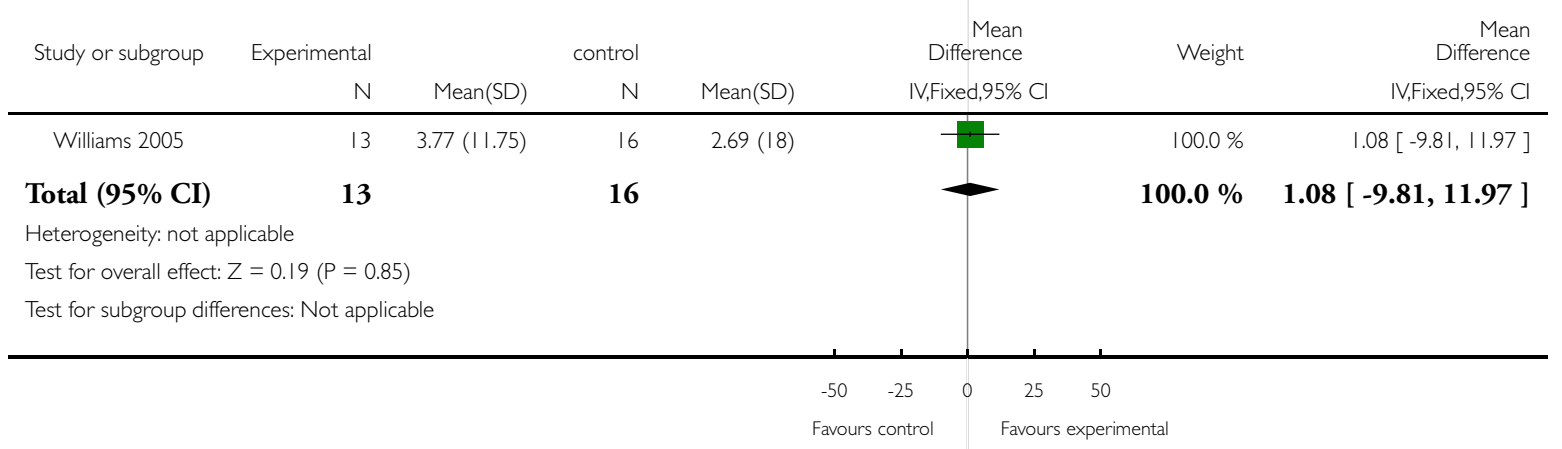


Analysis I.17. Comparison I Comparison one: Meditation, Outcome 17 Well-being at 8 weeks (mean change); meditation and massage.

Review: Spiritual and religious interventions for well-being of adults in the terminal phase of disease

Comparison: I Comparison one: Meditation

Outcome: 17 Well-being at 8 weeks (mean change); meditation and massage

\begin{tabular}{|c|c|c|c|c|c|c|c|c|}
\hline \multirow[t]{2}{*}{ Study or subgroup } & \multirow{2}{*}{$\begin{array}{r}\text { Experimental } \\
\mathrm{N}\end{array}$} & \multicolumn{3}{|c|}{ control } & \multicolumn{2}{|r|}{$\begin{array}{r}\text { Mean } \\
\text { Difference }\end{array}$} & \multirow[t]{2}{*}{ Weight } & \multirow{2}{*}{$\begin{array}{r}\text { Mean } \\
\text { Difference } \\
\text { IV,Fixed,95\% Cl }\end{array}$} \\
\hline & & Mean(SD) & $\mathrm{N}$ & Mean(SD) & & IV,Fixed,95\% Cl & & \\
\hline Williams 2005 & 13 & $-1.38(12.19)$ & 16 & $-2.56(15.04)$ & & & $100.0 \%$ & $1.18[-8.73,11.09]$ \\
\hline Total $(95 \% \mathrm{CI})$ & 13 & & 16 & & & 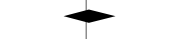 & $100.0 \%$ & $1.18[-8.73,11.09]$ \\
\hline \multicolumn{9}{|c|}{ Heterogeneity: not applicable } \\
\hline \multicolumn{9}{|c|}{ Test for overall effect: $Z=0.23(P=0.82)$} \\
\hline \multicolumn{9}{|c|}{ Test for subgroup differences: Not applicable } \\
\hline & & & & & -50 & -25 & 50 & \\
\hline & & & & & Favour & control & kperimental & \\
\hline
\end{tabular}

Analysis I.18. Comparison I Comparison one: Meditation, Outcome 18 Well-being at 68 weeks (mean change); meditation and massage.

Review: Spiritual and religious interventions for well-being of adults in the terminal phase of disease

Comparison: I Comparison one: Meditation

Outcome: 18 Well-being at 68 weeks (mean change); meditation and massage

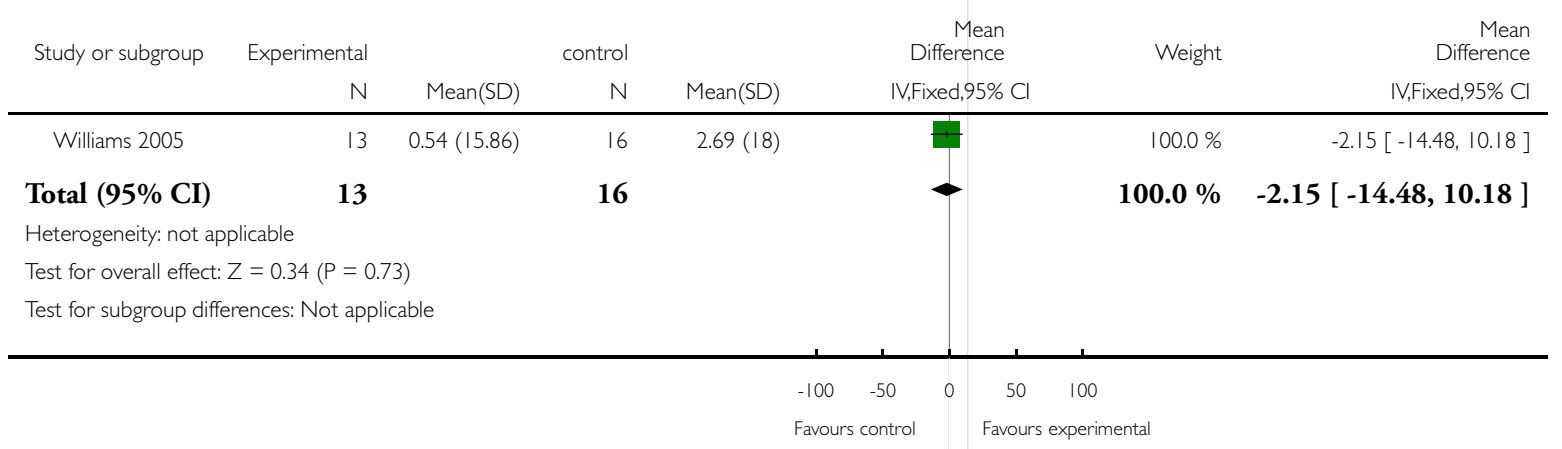


Analysis I.19. Comparison I Comparison one: Meditation, Outcome I9 Physical symptoms at 8 weeks (mean change); meditation.

Review: Spiritual and religious interventions for well-being of adults in the terminal phase of disease

Comparison: I Comparison one: Meditation

Outcome: 19 Physical symptoms at 8 weeks (mean change); meditation

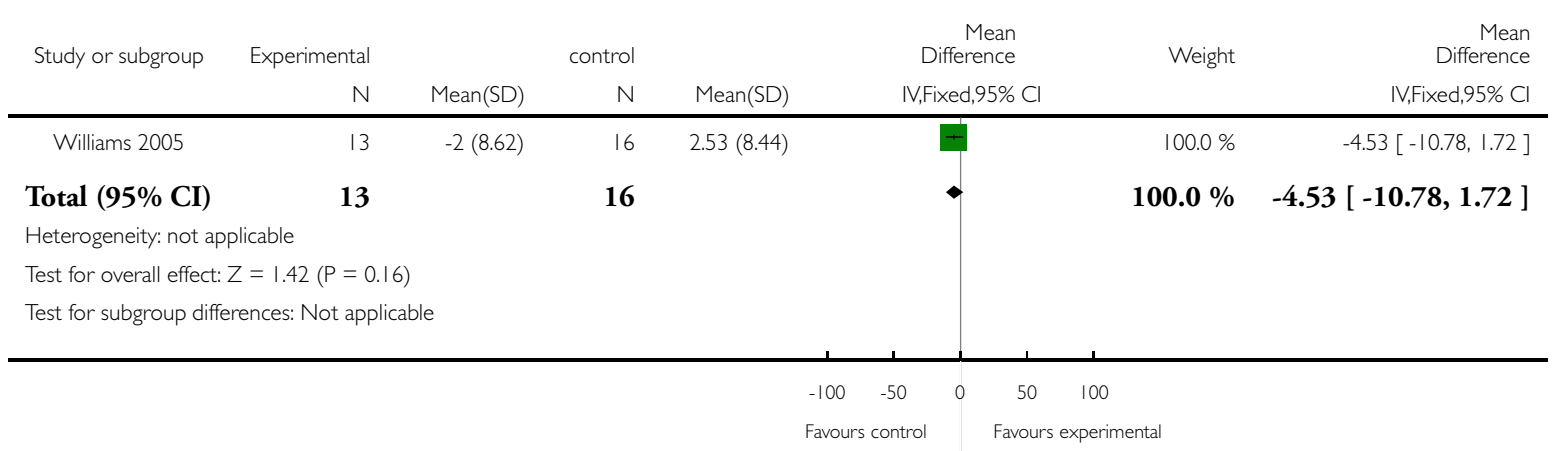

Analysis I.20. Comparison I Comparison one: Meditation, Outcome 20 Physical symptoms at 68 weeks (mean change); meditation.

Review: Spiritual and religious interventions for well-being of adults in the terminal phase of disease

Comparison: I Comparison one: Meditation

Outcome: 20 Physical symptoms at 68 weeks (mean change); meditation

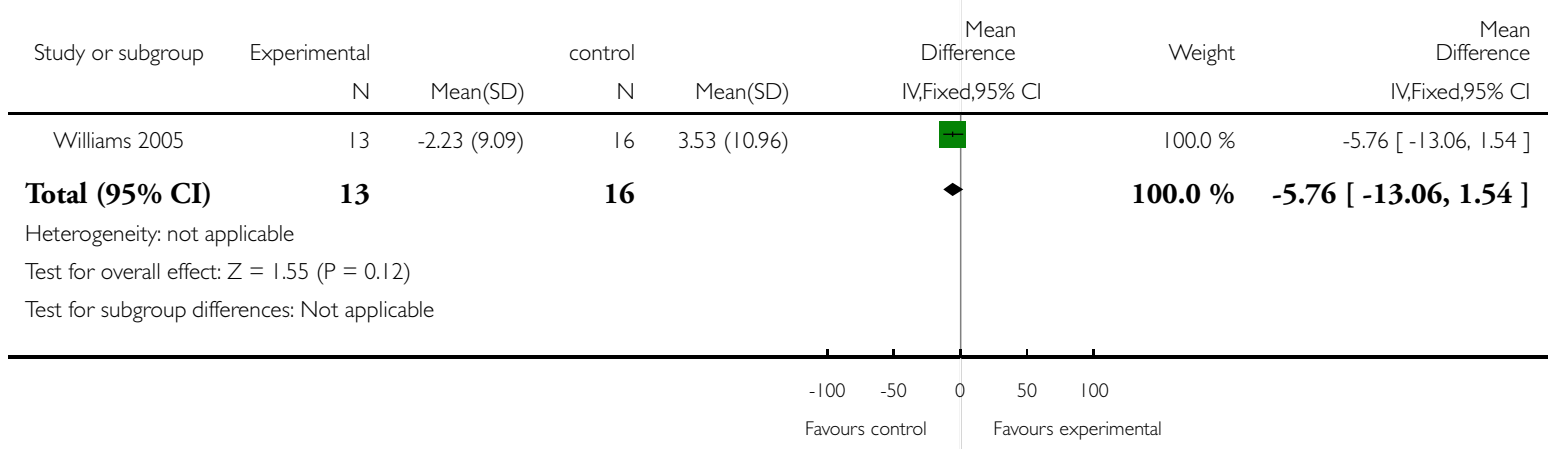


Analysis I.2I. Comparison I Comparison one: Meditation, Outcome 2 I Physical symptoms 8 weeks (mean change); meditation and massage.

Review: Spiritual and religious interventions for well-being of adults in the terminal phase of disease

Comparison: I Comparison one: Meditation

Outcome: 21 Physical symptoms 8 weeks (mean change); meditation and massage

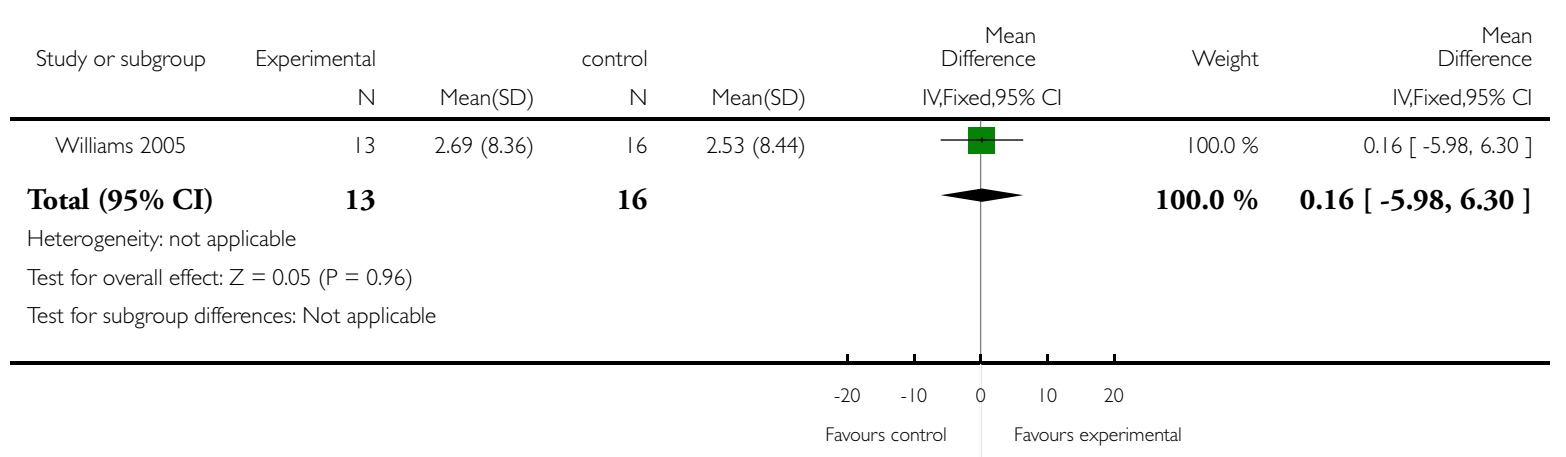

\section{Analysis I.22. Comparison I Comparison one: Meditation, Outcome 22 Physical symptoms at 68 weeks} (mean change); meditation and massage.

Review: Spiritual and religious interventions for well-being of adults in the terminal phase of disease

Comparison: I Comparison one: Meditation

Outcome: 22 Physical symptoms at 68 weeks (mean change); meditation and massage

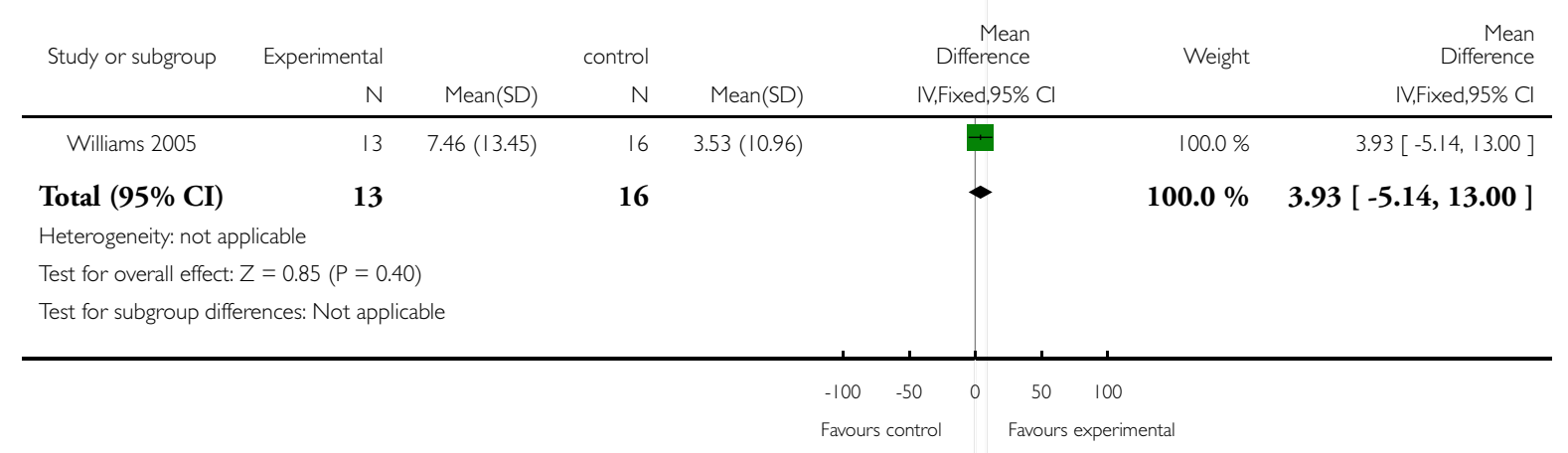


Analysis I.23. Comparison I Comparison one: Meditation, Outcome 23 Transcendence at 8 weeks (mean change); meditation.

Review: Spiritual and religious interventions for well-being of adults in the terminal phase of disease

Comparison: I Comparison one: Meditation

Outcome: 23 Transcendence at 8 weeks (mean change); meditation

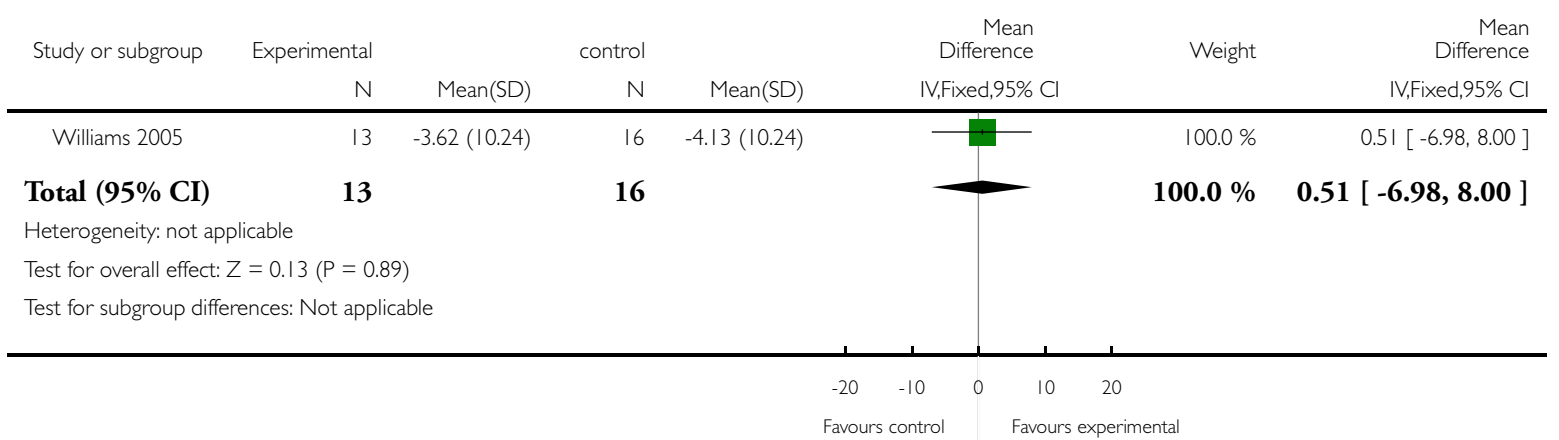

Analysis I.24. Comparison I Comparison one: Meditation, Outcome 24 Transcendence at 68 weeks (mean change); meditation.

Review: Spiritual and religious interventions for well-being of adults in the terminal phase of disease

Comparison: I Comparison one: Meditation

Outcome: 24 Transcendence at 68 weeks (mean change); meditation

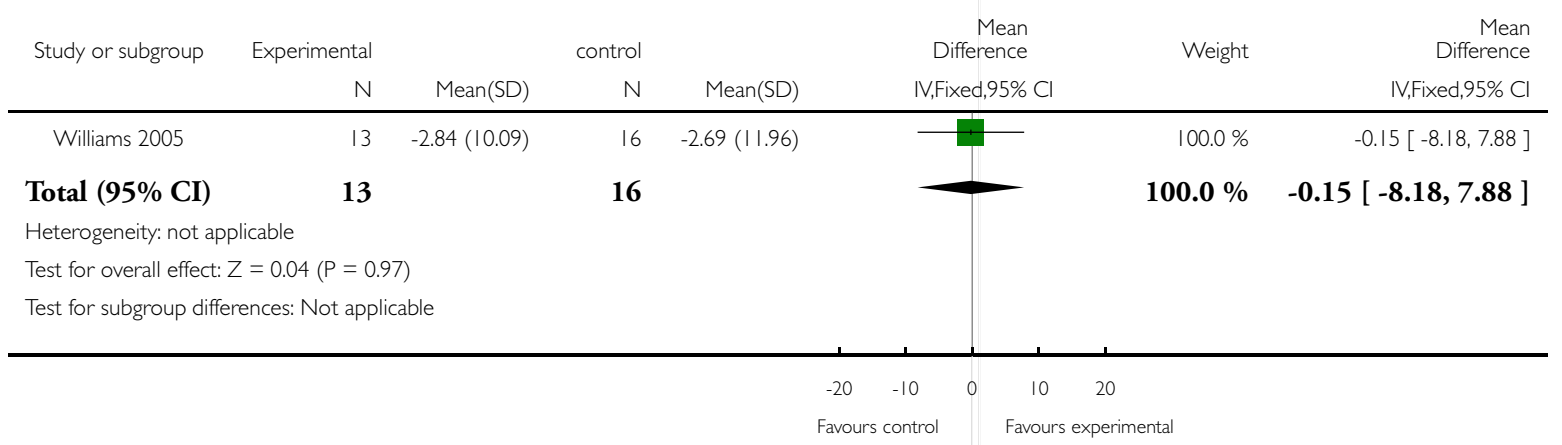


Analysis I.25. Comparison I Comparison one: Meditation, Outcome 25 Transcendence at 8 weeks (mean change); meditation and massage.

Review: Spiritual and religious interventions for well-being of adults in the terminal phase of disease

Comparison: I Comparison one: Meditation

Outcome: 25 Transcendence at 8 weeks (mean change); meditation and massage

\begin{tabular}{|c|c|c|c|c|c|c|c|c|}
\hline Study or subgroup & Experimental & \multicolumn{3}{|c|}{ control } & \multicolumn{2}{|r|}{$\begin{array}{r}\text { Mean } \\
\text { Difference }\end{array}$} & Weight & $\begin{array}{r}\text { Mean } \\
\text { Difference } \\
\text { IV,Fixed,95\% Cl }\end{array}$ \\
\hline Williams 2005 & 13 & $5.92(7.43)$ & 16 & $-4.13(10.24)$ & & + & $100.0 \%$ & $10.05[3.61,16.49]$ \\
\hline Total $(95 \% \mathrm{CI})$ & 13 & & 16 & & & $\bullet$ & $100.0 \%$ & $10.05[3.61,16.49]$ \\
\hline \multicolumn{9}{|c|}{ Heterogeneity: not applicable } \\
\hline & & & & & -100 & -50 & 100 & \\
\hline
\end{tabular}

Analysis I.26. Comparison I Comparison one: Meditation, Outcome 26 Transcendence at 68 weeks (mean change); meditation and massage.

Review: Spiritual and religious interventions for well-being of adults in the terminal phase of disease

Comparison: I Comparison one: Meditation

Outcome: 26 Transcendence at 68 weeks (mean change); meditation and massage

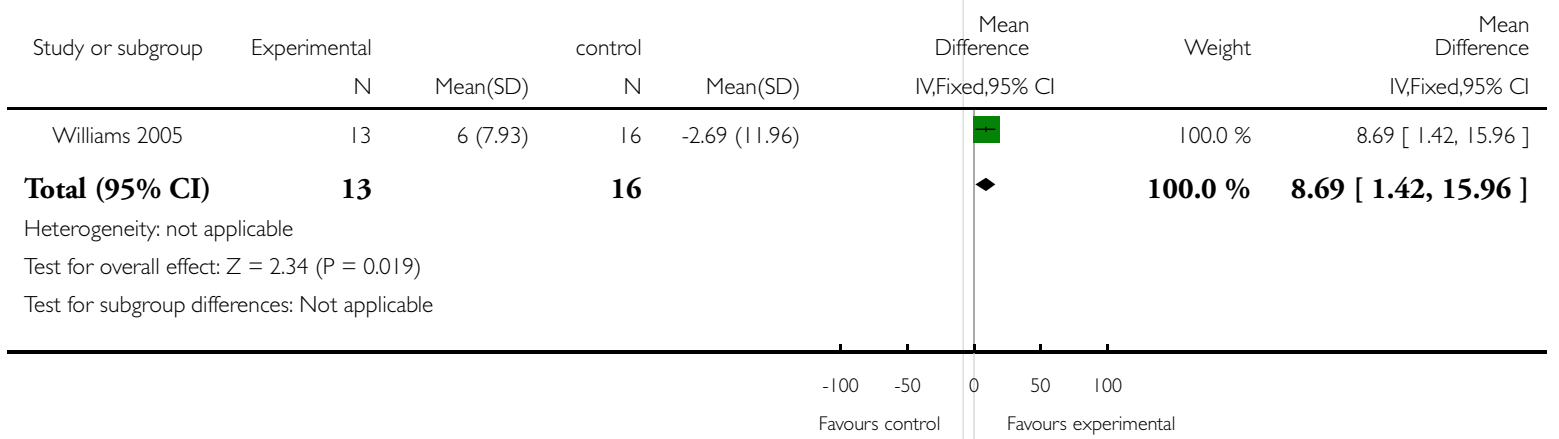


Analysis 2.I. Comparison 2 Comparison two: Multi-disciplinary interventions involving the support of a chaplain, Outcome I Emotional support.

Review: Spiritual and religious interventions for well-being of adults in the terminal phase of disease

Comparison: 2 Comparison two: Multi-disciplinary interventions involving the support of a chaplain

Outcome: I Emotional support

\begin{tabular}{|c|c|c|c|c|c|c|c|}
\hline \multirow[t]{2}{*}{ Study or subgroup } & \multirow{2}{*}{$\begin{array}{r}\text { Experimental } \\
\mathrm{N}\end{array}$} & \multicolumn{3}{|c|}{ Control } & \multirow{2}{*}{$\begin{array}{c}\text { Mean } \\
\text { Difference } \\
\text { IV,Fixed,95\% Cl }\end{array}$} & \multirow[t]{2}{*}{ Weight } & \multirow{2}{*}{$\begin{array}{r}\text { Mean } \\
\text { Difference } \\
\text { IV,Fixed,95\% Cl }\end{array}$} \\
\hline & & Mean(SD) & $\mathrm{N}$ & Mean(SD) & & & \\
\hline Gade 2008 & 184 & $7(1.4)$ & 177 & $6.7(1.5)$ & + & $100.0 \%$ & $0.30[0.00,0.60]$ \\
\hline Total $(95 \%$ CI) & 184 & & 177 & & $<$ & $100.0 \%$ & $0.30[0.00,0.60]$ \\
\hline \multicolumn{8}{|c|}{ Heterogeneity: not applicable } \\
\hline & & & & & 0 & 2 & \\
\hline & & & & & Favours & perimental & \\
\hline
\end{tabular}

Analysis 2.2. Comparison 2 Comparison two: Multi-disciplinary interventions involving the support of a chaplain, Outcome 2 Quality of life.

Review: Spiritual and religious interventions for well-being of adults in the terminal phase of disease

Comparison: 2 Comparison two: Multi-disciplinary interventions involving the support of a chaplain

Outcome: 2 Quality of life

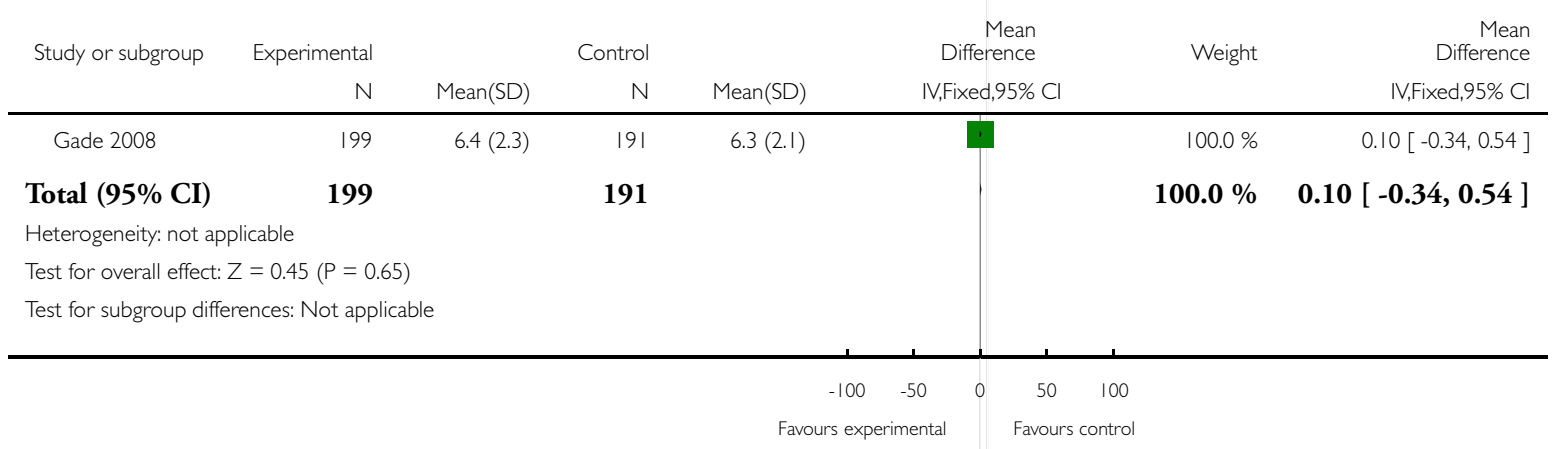


Analysis 2.3. Comparison 2 Comparison two: Multi-disciplinary interventions involving the support of a chaplain, Outcome 3 Symptom severity.

Review: Spiritual and religious interventions for well-being of adults in the terminal phase of disease

Comparison: 2 Comparison two: Multi-disciplinary interventions involving the support of a chaplain

Outcome: 3 Symptom severity

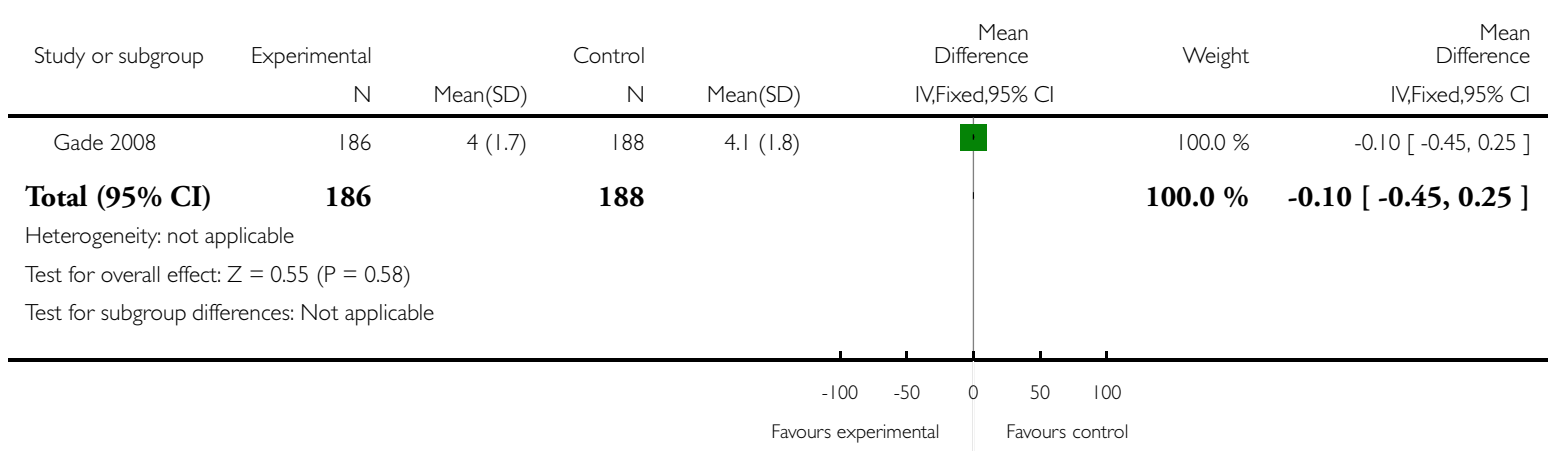

Analysis 2.4. Comparison 2 Comparison two: Multi-disciplinary interventions involving the support of a chaplain, Outcome 4 Spiritually support.

Review: Spiritual and religious interventions for well-being of adults in the terminal phase of disease

Comparison: 2 Comparison two: Multi-disciplinary interventions involving the support of a chaplain

Outcome: 4 Spiritually support

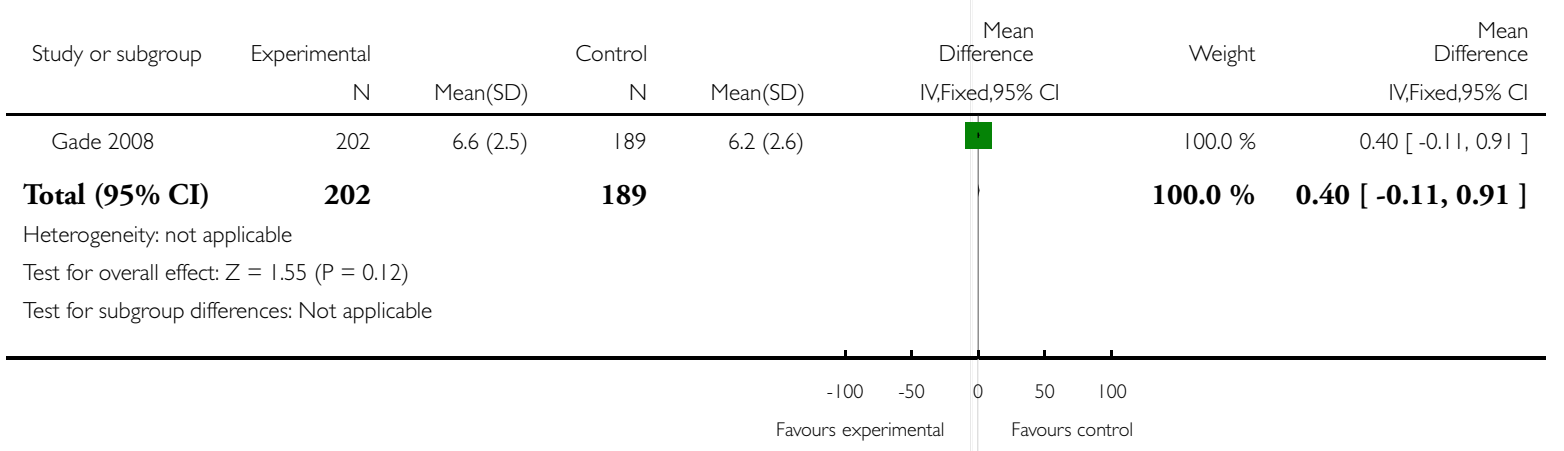


Analysis 2.5. Comparison 2 Comparison two: Multi-disciplinary interventions involving the support of a chaplain, Outcome 5 Clinic visits.

Review: Spiritual and religious interventions for well-being of adults in the terminal phase of disease

Comparison: 2 Comparison two: Multi-disciplinary interventions involving the support of a chaplain

Outcome: 5 Clinic visits

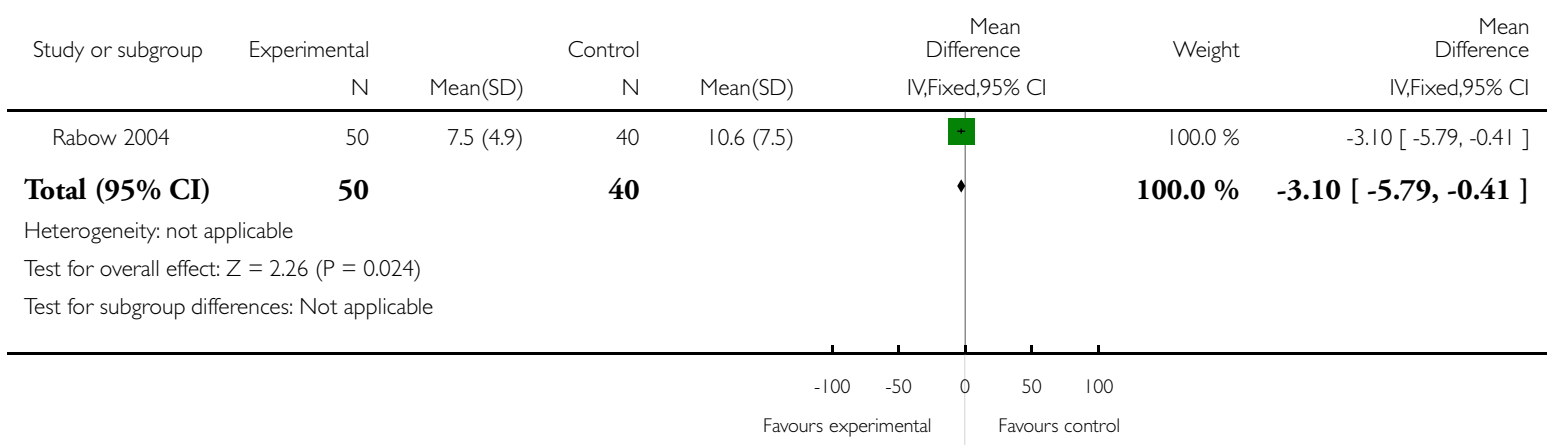

Analysis 2.6. Comparison 2 Comparison two: Multi-disciplinary interventions involving the support of a chaplain, Outcome 6 Urgent care visits.

Review: Spiritual and religious interventions for well-being of adults in the terminal phase of disease

Comparison: 2 Comparison two: Multi-disciplinary interventions involving the support of a chaplain

Outcome: 6 Urgent care visits

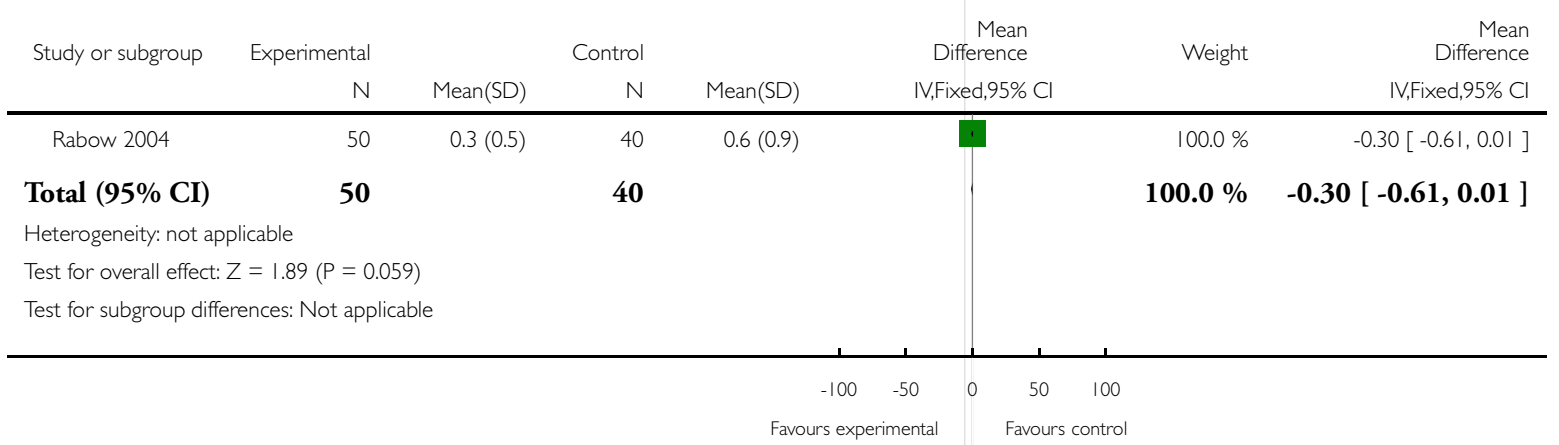


Analysis 2.7. Comparison 2 Comparison two: Multi-disciplinary interventions involving the support of a chaplain, Outcome 7 Hospital admissions.

Review: Spiritual and religious interventions for well-being of adults in the terminal phase of disease

Comparison: 2 Comparison two: Multi-disciplinary interventions involving the support of a chaplain

Outcome: 7 Hospital admissions

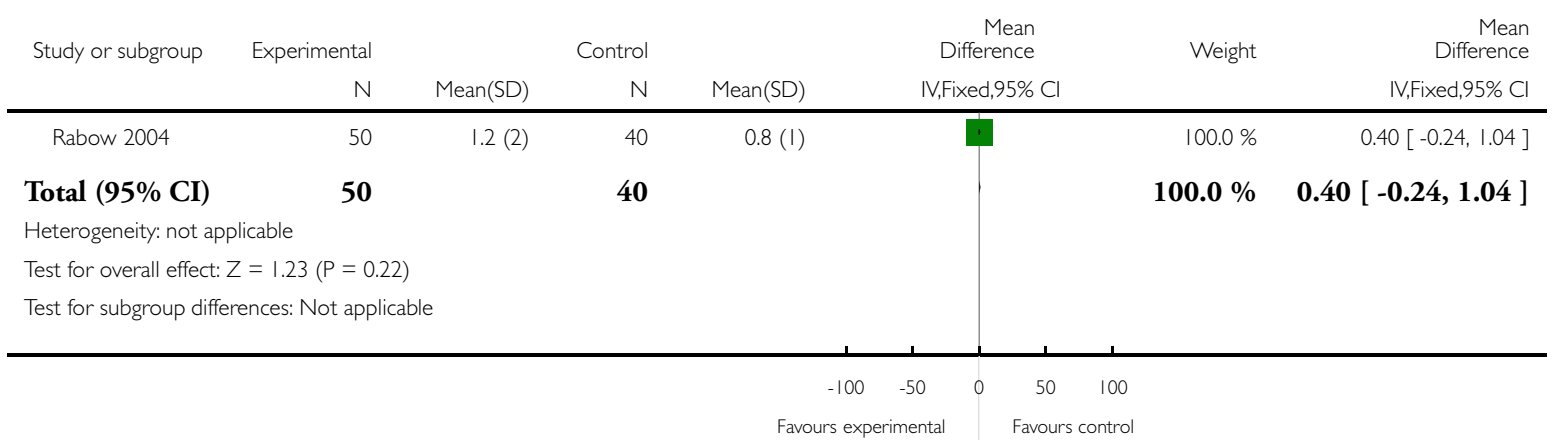

Analysis 2.8. Comparison 2 Comparison two: Multi-disciplinary interventions involving the support of a chaplain, Outcome 8 Emergency department visits.

Review: Spiritual and religious interventions for well-being of adults in the terminal phase of disease

Comparison: 2 Comparison two: Multi-disciplinary interventions involving the support of a chaplain

Outcome: 8 Emergency department visits

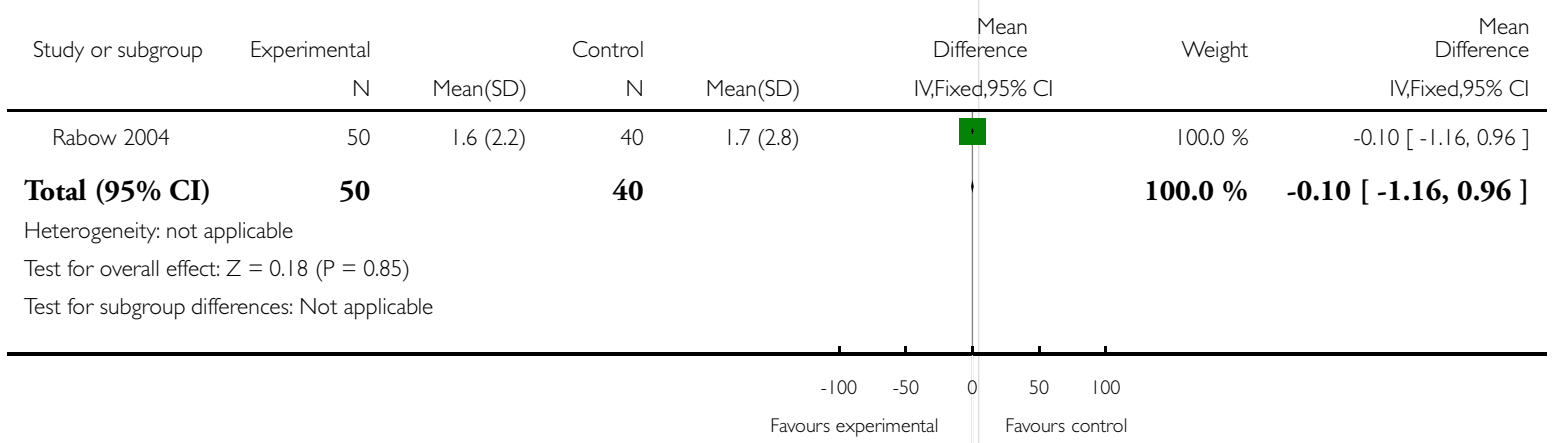


Analysis 2.9. Comparison 2 Comparison two: Multi-disciplinary interventions involving the support of a chaplain, Outcome 9 Specialist visits.

Review: Spiritual and religious interventions for well-being of adults in the terminal phase of disease

Comparison: 2 Comparison two: Multi-disciplinary interventions involving the support of a chaplain

Outcome: 9 Specialist visits

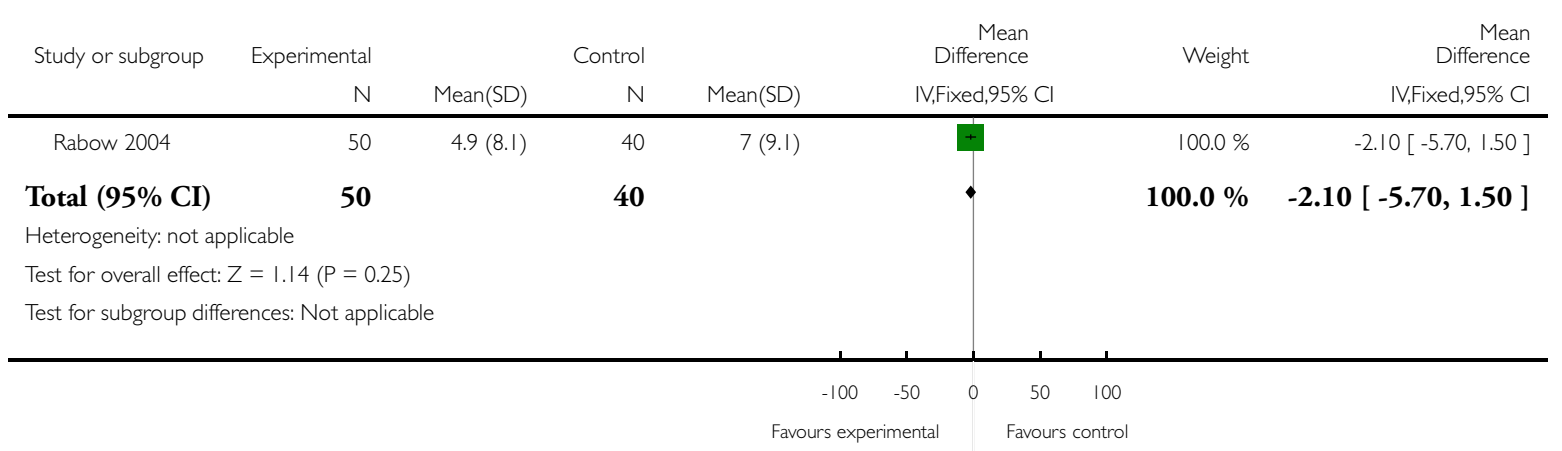

Analysis 2.10. Comparison 2 Comparison two: Multi-disciplinary interventions involving the support of a chaplain, Outcome 10 Total hospital days.

Review: Spiritual and religious interventions for well-being of adults in the terminal phase of disease

Comparison: 2 Comparison two: Multi-disciplinary interventions involving the support of a chaplain

Outcome: 10 Total hospital days

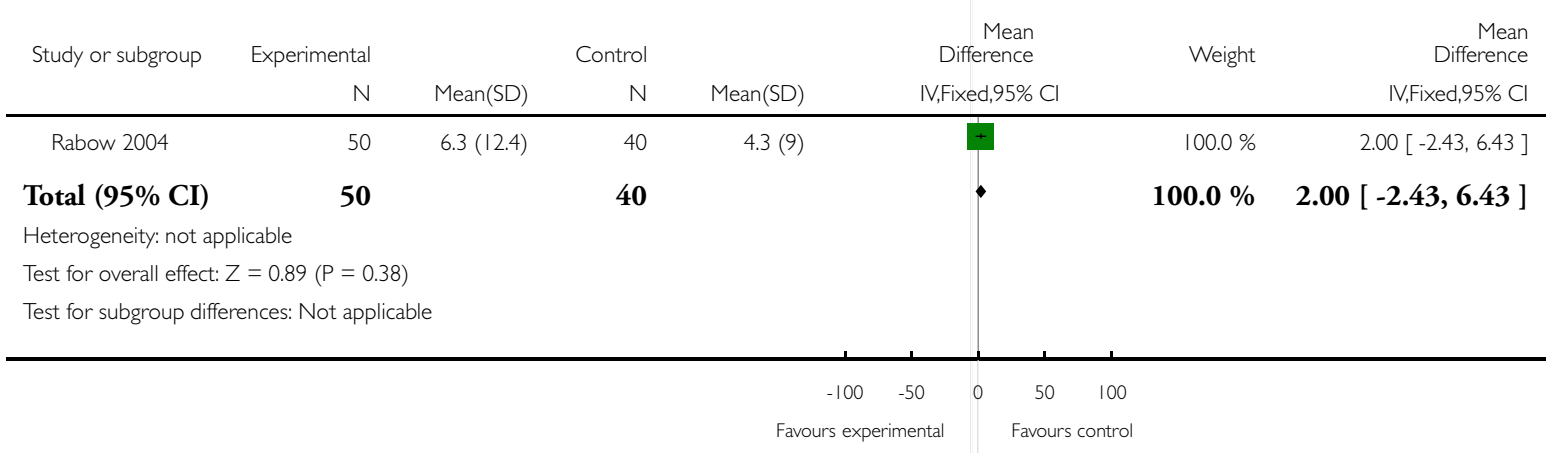


Analysis 2.1 I. Comparison 2 Comparison two: Multi-disciplinary interventions involving the support of a chaplain, Outcome II Admissions to intensive care.

Review: Spiritual and religious interventions for well-being of adults in the terminal phase of disease

Comparison: 2 Comparison two: Multi-disciplinary interventions involving the support of a chaplain

Outcome: II Admissions to intensive care

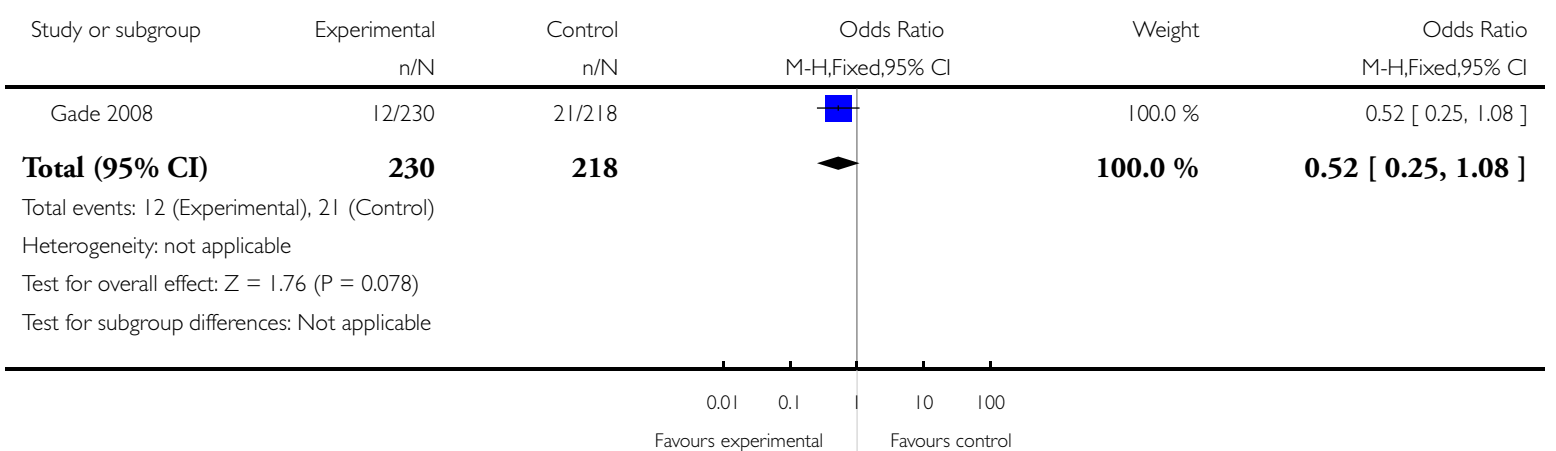

Analysis 2.12. Comparison 2 Comparison two: Multi-disciplinary interventions involving the support of a chaplain, Outcome 12 Satisfaction of care environment.

Review: Spiritual and religious interventions for well-being of adults in the terminal phase of disease

Comparison: 2 Comparison two: Multi-disciplinary interventions involving the support of a chaplain

Outcome: 12 Satisfaction of care environment

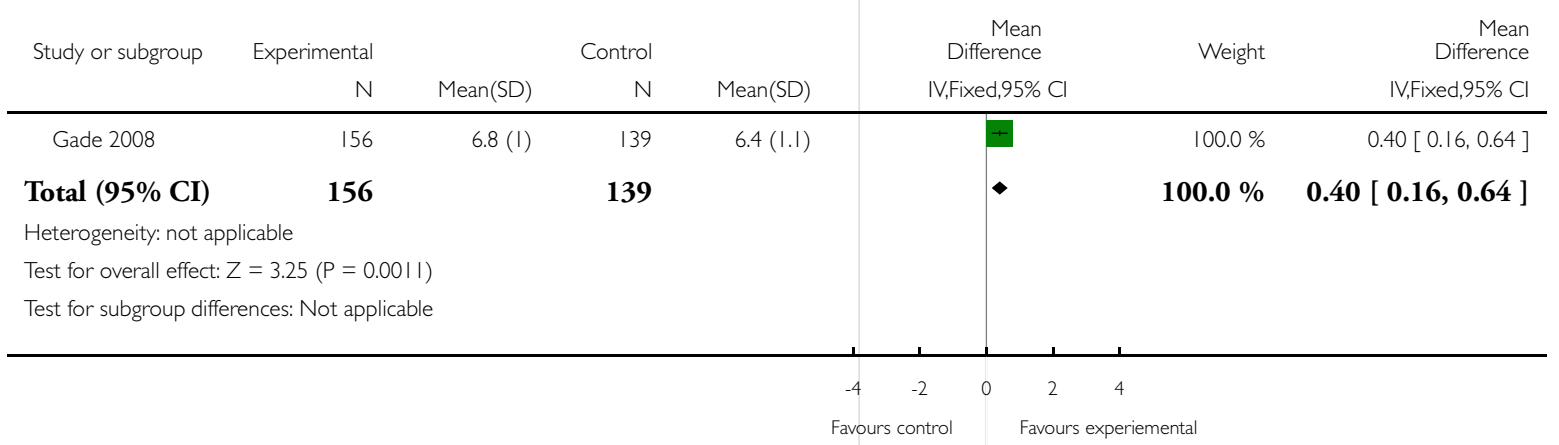


Analysis 2.13. Comparison 2 Comparison two: Multi-disciplinary interventions involving the support of a chaplain, Outcome 13 Satisfaction with care staff.

Review: Spiritual and religious interventions for well-being of adults in the terminal phase of disease

Comparison: 2 Comparison two: Multi-disciplinary interventions involving the support of a chaplain

Outcome: 13 Satisfaction with care staff

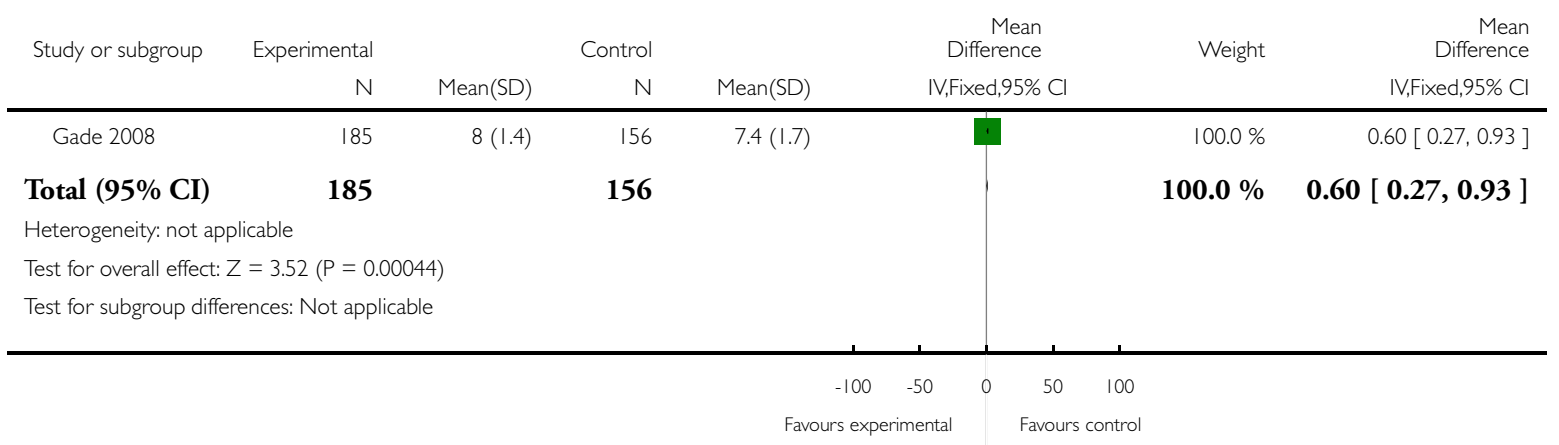

\section{A P P E N D I C E S}

\section{Appendix I. CENTRAL search strategy}

The search terms we used reflected components of our research question:

A) Spirituality interventions

B) Advanced disease

\#1 MeSH descriptor Spiritual Therapies explode all trees

\#2 $\mathrm{MeSH}$ descriptor Religion explode all trees

\#3 religious or religion* or spirit* or soul or religiousity

\#4 meditat*

\#5 pray*

\#6 pastoral near/3 (care or caring)

\#7 anoint*

\#8 "laying on of hands"

\#9 Deity or divinity or divine

\#10 faith* or hope or connect* or identity

\#11 psychic next healing or "inner peace"

\#12 yoga

\#13 church* or cleric or clergyman or priest or preacher

\#14 shamanism or mystic* or transcend* or esoteric

\#15 existential or salutogenesis

\#16 Buddhism or Buddist* or Christian* or catholic* or "eastern orthodoxy" or "Jehovah* witness" or protestant* or HIndu* or Islam* or Judaism or Taoism or Sikk or Rastafari

\#17 confucianism or mystic* or "eastern philosophy"

Spiritual and religious interventions for well-being of adults in the terminal phase of disease (Review)

Copyright $\odot 2012$ The Cochrane Collaboration. Published by John Wiley \& Sons, Ltd. 
\#18 God or "supreme being" or "higher being"

\#19 belief* or believe*

\#20 \#1 OR \#2 OR \#3 OR \#4 OR \#5 OR \#6 OR \#7 OR \#8 OR \#9 OR \#10 OR \#11 OR \#12 OR \#13 OR \#14 OR \#15 OR \#16

OR \#17 OR \#18 OR \#19)

\#21 MeSH descriptor Palliative Care explode all trees

\#22 MeSH descriptor Terminal Careexplode all trees

\#23 MeSH descriptor Hospice Careexplode all trees

\#24 hospice near (care or caring)

\#25 ("end stage" or "late stage") and (disease* or illness)

\#26 dying or "end of life"

\#27 “terminal* ill*” or "terminal stage"

\#28 advanced near (disease* or cancer or illness)

\#29 palliat* $^{*}$

\#30 "advanced directive"

\#31 (\#21 OR \#22 OR \#23 OR \#24 OR \#25 OR \#26 OR \#27 OR \#28 OR \#29 OR \#30)

\#32 (\#20 AND \#31)

\section{Appendix 2. Other search strategies}

\section{MEDLINE search strategy}

1 exp Spiritual Therapies/

2 exp Religion/

3 (religious or religion* or spirit* or soul or religiousity).mp.

4 meditat*.mp

5 (pray* or prey*).mp.

6 ((pastoral adj3 care) or (pastoral adj3 caring)).mp.

7 anoint*.mp.

8 "laying on of hands".mp.

9 ((belief* or believe*) and (relig* or spiritual)).mp.

10 (Deity or divinity or divine).mp.

11 faith*.mp.

12 ("psychic healing" or "inner peace").mp.

13 yoga.mp.

14 (church* $^{*}$ or cleric or clergy* or priest $^{*}$ or preacher* or vicar* $^{*}$ or (minister* adj10 religi*) or (minister adj10 church)).mp.

15 (shamanism or mystic* or transcend*or esoteric).mp.

16 (existential or salutogenesis).mp.

17 (Buddhism or Buddhist* or Christian* or catholic* or "eastern orthodoxy" or "Jehovah* witness*” or protestant* or Hindu* or Islam* or Judaism or Tao* or Sikh* or Rastafari*).mp.

18 (confucianism or mystic* or "eastern philosophy").mp.

19 (God or "supreme being" or "higher being").mp.

20 Palliative Care/

21 Terminal Care/

22 exp Hospice Care/

23 ((hospice adj care) or (hospice adj caring)).mp.

24 (("end stage" or "late stage") and (disease* or illness)).mp.

25 palliat*.mp.

26 "advanced directive*".mp.

27 ("dying" or "end of life").mp.

28 ("terminal* ill*" or "terminal stage").mp.

29 (advanced adj6 (disease* or cancer or illness)).mp. 
301 or 2 or 3 or 4 or 5 or 6 or 7 or 8 or 9 or 10 or 11 or 12 or 13 or 14 or 15 or 16 or 17 or 18 or 19

3120 or 21 or 22 or 23 or 24 or 25 or 26 or 27 or 28 or 29

$32 \quad 30$ and 31

key:

[mp = title, original title, abstract, name of substance word, subject heading word, unique identifier]

\section{EMBASE search strategy - via OVID}

1 exp alternative medicine/

2 RELIGION/

3 (religious or religion* or spirit* or soul or religiousity).mp.

4 meditat*.mp.

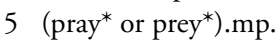

6 ((pastoral adj3 care) or (pastoral adj3 caring)).mp.

7 anoint*.mp.

8 "laying on of hands".mp.

9 ((belief* or believe*) and (relig* or spiritual)).mp.

10 (Deity or divinity or divine).mp.

11 faith*.mp.

12 ("psychic healing" or "inner peace").mp.

13 yoga.mp.

14 (church* or cleric or clergy* or priest* or preacher* or vicar* or (minister* adj10 religi*) or (minister adj10 church)).mp.

15 (shamanism or mystic* or transcend*or esoteric).mp.

16 (existential or salutogenesis).mp.

17 (Buddhism or Buddhist* or Christian* or catholic* or "eastern orthodoxy" or "Jehovah* witness" or protestant* or Hindu* or Islam* or Judaism or Tao* or Sikh* or Rastafari*).mp.

18 (confucianism or mystic* or "eastern philosophy”).mp.

19 (God or "supreme being" or "higher being").mp.

20 exp palliative therapy/

21 Terminal Care/

22 Hospice Care/

23 ((hospice adj care) or (hospice adj caring)).mp.

24 (("end stage" or "late stage") and (disease* or illness)).mp.

25 palliat*.mp.

26 "advanced directive*”.mp

27 ("dying" or "end of life").mp.

28 ("terminal* ill*" or "terminal stage").mp.

29 (advanced adj6 (disease* or cancer or illness)).mp.

301 or 2 or 3 or 4 or 5 or 6 or 7 or 8 or 9 or 10 or 11 or 12 or 13 or 14 or 15 or 16 or 17 or 18 or 19

3120 or 21 or 22 or 23 or 24 or 25 or 26 or 27 or 28 or 29

3230 and 31

key:

[mp = title, abstract, subject headings, heading word, drug trade name, original title, device manufacturer, drug manufacturer]

\section{AMED search strategy}

1 exp Spiritual Therapies/

2 exp Religion/

3 (religious or religion* or spirit* or soul or religiousity).mp.

4 meditat*.mp

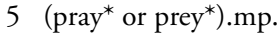

6 ((pastoral adj3 care) or (pastoral adj3 caring)).mp.

7 anoint*.mp. 
8 "laying on of hands".mp.

9 ((belief* or believe*) and (relig* or spiritual)).mp.

10 (Deity or divinity or divine).mp.

11 faith*.mp. [mp=abstract, heading words, title]

12 ("psychic healing" or "inner peace").mp.

13 yoga.mp.

14 (church* $^{*}$ or cleric or clergy* or priest* or preacher* or vicar* or (minister* adj10 religi*) or (minister adj10 church)).mp.

15 (shamanism or mystic* or transcend*or esoteric).mp.

16 (existential or salutogenesis).mp.

17 (Buddhism or Buddhist* or Christian* or catholic* or "eastern orthodoxy" or "Jehovah* witness*" or protestant* or Hindu* or Islam* or Judaism or Tao* or Sikh* or Rastafari*).mp.

18 (confucianism or mystic* or "eastern philosophy").mp.

19 (God or "supreme being" or "higher being").mp.

20 Palliative Care/

21 Terminal Care/

22 Hospice Care/

23 ((hospice adj care) or (hospice adj caring)).mp.

24 (("end stage" or "late stage") and (disease* or illness)).mp.

25 palliat*.mp.

26 "advanced directive*".mp.

27 ("dying" or "end of life").mp.

28 ("terminal* ill*" or "terminal stage").mp.

29 (advanced adj6 (disease* or cancer or illness)).mp.

301 or 2 or 3 or 4 or 5 or 6 or 7 or 8 or 9 or 10 or 11 or 12 or 13 or 14 or 15 or 16 or 17 or 18 or 19

3120 or 21 or 22 or 23 or 24 or 25 or 26 or 27 or 28 or 29

3230 and 31

key:

[mp = abstract, heading words, title $]$

\section{PsycINFO search strategy}

1 exp Spirituality/ or spiritual therapies.

2 exp Religion/

3 (religious or religion* or spirit* or soul or religiousity).mp.

4 meditat*.mp.

5 (pray* or prey*).mp.

6 ((pastoral adj3 care) or (pastoral adj3 caring)).mp.

7 anoint*.mp.

8 "laying on of hands".mp.

9 ((belief* or believe*) and (relig* or spiritual)).mp.

10 (Deity or divinity or divine).mp.

11 faith*.mp. $^{*}$.

12 ("psychic healing" or "inner peace").mp.

13 yoga.mp.

14 (church* or cleric or clergy* or priest* or preacher* or vicar* or (minister* adj10 religi*) or (minister adj10 church)).mp.

15 (shamanism or mystic* or transcend*or esoteric).mp.

16 (existential or salutogenesis).mp.

17 (Buddhism or Buddhist* or Christian* or catholic* or "eastern orthodoxy" or "Jehovah* witness*" or protestant* or Hindu* or Islam* or Judaism or Tao* or Sikh* or Rastafari*).mp.

18 (confucianism or mystic* or "eastern philosophy").mp.

19 (God or "supreme being" or "higher being").mp.

20 Palliative Care/

21 exp "Death and Dying"/ or exp Terminally Ill Patients/ or terminal care. 
22 exp Hospice/ or hospice care.

23 ((hospice adj care) or (hospice adj caring)).mp.

24 (("end stage" or "late stage") and (disease* or illness)).mp.

25 palliat*.mp.

26 "advanced directive*".mp.

27 ("dying" or "end of life").mp.

28 ("terminal* ill*" or "terminal stage").mp.

29 (advanced adj6 (disease* or cancer or illness)).mp.

301 or 2 or 3 or 4 or 5 or 6 or 7 or 8 or 9 or 10 or 11 or 12 or 13 or 14 or 15 or 16 or 17 or 18 or 19

3120 or 21 or 22 or 23 or 24 or 25 or 26 or 27 or 28 or 29

3230 and 31

key:

[mp = title, abstract, heading word, table of contents, key concepts]

\section{CINAHL search strategy}

1 exp Spirituality/ or spiritual care.

2 exp Religion and religions/

3 (religious or religion* or spirit* or soul or religiousity).mp.

4 meditat*.mp.

5 (pray* or prey*).mp.

6 ((pastoral adj3 care) or (pastoral adj3 caring)).mp.

7 anoint*.mp.

8 "laying on of hands".mp.

9 ((belief* or believe*) and (relig* or spiritual)).mp.

10 (Deity or divinity or divine).mp.

11 faith*.mp.

12 ("psychic healing" or "inner peace").mp.

13 yoga.mp.

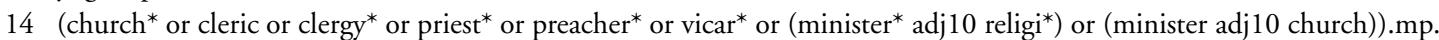

15 (shamanism or mystic* or transcend*or esoteric).mp.

16 (existential or salutogenesis).mp.

17 (Buddhism or Buddhist* or Christian* or catholic* or "eastern orthodoxy" or "Jehovah* witness*" or protestant* or Hindu* or Islam* or Judaism or Tao* or Sikh* or Rastafari*).mp.

18 (confucianism or mystic* or "eastern philosophy").mp.

19 (God or "supreme being" or "higher being").mp.

20 Palliative Care/

21 exp "Death and Dying"/ or exp Terminally Ill Patients/ or terminal care.mp.

22 exp Hospice/ or hospice care.mp.

23 ((hospice adj care) or (hospice adj caring)).mp.

24 (("end stage" or "late stage") and (disease* or illness)).mp.

25 palliat*.mp

26 "advanced directive*”.mp

27 ("dying" or "end of life").mp.

28 ("terminal* ill*" or "terminal stage").mp.

29 (advanced adj6 (disease* or cancer or illness)).mp.

301 or 2 or 3 or 4 or 5 or 6 or 7 or 8 or 9 or 10 or 11 or 12 or 13 or 14 or 15 or 16 or 17 or 18 or 19

3120 or 21 or 22 or 23 or 24 or 25 or 26 or 27 or 28 or 29

3230 and 31

\section{Search strategy for smaller citation databases}


We searched the following databases National Health Service Research Register, ATLA, ASSIA, Anthropology Plus, Social Services Abstracts and Sociological Abstracts. As these held fewer citations we only searched them using terms for participants.

\section{H I S T O R Y}

Protocol first published: Issue 1, 2009

Review first published: Issue 5, 2012

\section{CONTRIBUTIONSOFAUTHORS}

LJ, PS, MK: conceptualised topic area. BC wrote the protocol.

BC: undertook the data searches and together with $\mathrm{LJ}$ selected studies and data extraction. BC drafted the review.

AT: advised on protocol development and commented on the findings and conclusions. MV advised on statistical analysis and provided commentary on the review findings and conclusions.

LJ, PS, MK, MV: protocol and methodology advice, provided commentary on the review findings and conclusions, and contributed to the final report.

$\mathrm{BC}, \mathrm{LJ}$ will be responsible for updating the review.

\section{DECLARATIONSOF INTEREST}

None known.

\section{SOURCESOFSUPPORT}

\section{Internal sources}

- Marie Curie Palliative Care Research Unit, London, UK.

- Royal Free and University College Medical School, London, UK.

\section{External sources}

- No sources of support supplied

\section{DIFFERENCES BETWEEN PROTOCOLAND REVIEW}

Refinement of inclusion criteria. This was necessary as it only became apparent that they were needed during our in-depth review of papers. Refinements were for the purpose of clarification of inclusion. More detail is also provided on methods to deal with missing data. 
I NDEX TERMS

\section{Medical Subject Headings (MeSH)}

*Religion; *Spirituality; Massage [psychology]; Meditation [psychology]; Palliative Care [organization \& administration]; Quality of Life; Randomized Controlled Trials as Topic; Terminally Ill [* psychology]

\section{MeSH check words}

Adult; Humans 